\title{
Physiological and molecular mechanisms of brassinosteroid-induced tolerance to high and low temperature in plants
}

\author{
I. SADURA and A. JANECZKO* \\ The Franciszek Górski Institute of Plant Physiology, Polish Academy of Sciences, \\ PL-30239 Krakow, Poland
}

\begin{abstract} proline.

Brassinosteroids (BRs) were isolated for the first time from Brassica napus pollen (Grove et al. 1979). This group currently includes more than 70 steroids that differ in structure and physiological activity. BRs are present in a free form and as conjugates in higher plants and algae (Bajguz and Tretyn 2003). In higher plants, BRs occur in all organs in a nano- and pico-gram amount per gram of fresh mass. BRs can be divided into three main groups depending on the number of carbon atoms in the molecule: $\mathrm{C}_{27}, \mathrm{C}_{28}$, and $\mathrm{C}_{29}$. Sterols are precursors in the
\end{abstract}

Brassinosteroids (BRs) are plant hormones that were isolated for the first time in the 1970s. This group currently includes more than 70 compounds that differ in their structure and physiological activity. BRs are present in plants in a free form or in the form of conjugates. BRs are known as plant growth regulators, but they also play a role in the plant response to environmental stresses. In the case of plants that are exposed to low/high temperature, exogenous BRs can counteract growth inhibition and reduce biomass losses as well as increase plant survival. BRs show a multidirectional activity in regulating the metabolism of plants exposed to extreme temperatures. The following BRs actions can be distinguished: changes in membrane physicochemical properties, regulation of the expression of selected genes (including stress-responsive genes), as well as indirect effects on metabolism through other hormones or signalling molecules (such as hydrogen peroxide). This review summarizes the current knowledge about the effects of BRs on the physiological and biochemical processes that occur in plants during exposure to low or high temperatures.

Additional key words: plant acclimation, cell membranes, cold, freezing, gene expression, heat, oxidative damage, photosynthesis,

\section{Introduction: discovery, occurrence, biosynthesis and hormonal nature of brassinosteroids}

synthesis of all BRs, and campesterol and 24- $\beta$-methylcholesterol are considered to be precursors of $\mathrm{C}_{28}$ BRs (Fujioka and Yokota 1997, Takatsuto et al. 1999, Park et al. 2000, Schaller 2003, Kim et al. 2004, 2006), cholesterol of $\mathrm{C}_{27}$ BRs (Fujioka and Yokota 1997, Schaller 2003, Kim et al. 2004, 2006), and sitosterol of $\mathrm{C}_{29}$ BRs (Fujioka and Yokota 1997, Takatsuto et al. 1999, Schaller 2003, Kim et al. 2006) (Fig. 1). The main and the first BR biosynthetic pathway was discovered in cultured cells of Catharanthus roseus and Arabidopsis

Submitted 27 October 2017, last revision 12 February 2018, accepted 7 March 2018.

Abbreviations: ABA - abscisic acid; APX - ascorbate peroxidase; AsA - ascorbic acid; BAK1 - BRI1 associated receptor kinase1; BES1 - bri1-EMS-supressor1; BIN2 - brassinosteroid insensitive2 kinase; BR - brassinosteroid; BRI1 - cell surface receptor kinase; Brz - brassinazole; BSK1 - brassinosteroid-signalling kinase1; BZR1 - brassinazole resistant1; CAT - catalase; CBFs C-repeat/dehydration responsive element binding factors; CI - chilling injury; COR - cold-responsive proteins; DHAR dehydroascorbate reductase; E - transpiration rate; ETR - electron transport rate; $F_{v} / F_{m}$ - maximum quantum efficiency of PS II photochemistry; $F_{v}$ ' $/ F_{m}$ ' - efficiency of open reaction centres in light; $g_{s}$ - stomatal conductance; GR - glutathione reductase; GSH reduced glutathione; HSP - heat shock protein; MDA - malondialdehyde; MDAR - monodehydroascorbate reductase; PN - net photosynthetic rate; POD - peroxidase; qP - photochemical quenching coefficient; ROS - reactive oxygen species; Rubisco ribulose--1,5-bis-phosphate carboxylase/oxygenase; SOD - superoxide dismutase; ФPSI - effective quantum yield of PS II photochemistry.

Acknowledgment: The work was funded by the grant of the National Science Centre (2016-2018) No. 2015/17/B/NZ9/01695 (Poland).

* Corresponding author; fax: (+048) 124251844, e-mail: ania@belanna.strefa.pl 
thaliana for BR type $\mathrm{C}_{28}$ brassinolide (Yokota et al. 1990, Fuijoka and Yokota 1997, Clouse 2015). The intermediates in this pathway are cathasterone, teasterone, typhasterol, and castasterone in the early C6 oxidation pathway and 6-deoxocathasterone, 6-deoxoteasterone, 6-deoxotyphasterol, and 6-deoxocastasterone in the late C6 oxidation pathway (Fujioka and Yokota 1997).

Brassinosteroids are perceived by the cell surface receptor kinase, BRI1. Binding BR to the extracellular domain of BRI1 induces activation and dimerization of kinase with its co-receptor kinase BAK1 (BRI1associated receptor kinase1) or its homologue SERK1 (somatic embryogenesis receptor kinase 1). Sequential trans-phosphorylation between the kinase domains of BRI1 and BAK1 activates the kinases and BRI1 in turn phosphorylates the members of two groups of plasma membrane-anchored cytoplasmic kinases, BSK1 (brasinosteroid-signaling kinase1) and CDG1 (constitutive differential growth1). CDG1, and possibly also BSK1, phosphorylates the BRI1-supressor1 (BSU1) phosphatase, which then dephosphorylates and inactivates the GSK3-like kinase brassinosteroid insenitive2 (BIN2). BIN2 directly regulates the phosphorylation status and nuclear accumulation of two homologous transcription factors, BZR1 (brasinazole resistant1) and BES1 (bri1-EMS-suppressor1) (Wang et al. 2006, Li and Jin 2007, Wang et al. 2014).

Although it was already known in the 1970s that the exogenous BRs stimulates the elongation of stems and cell division in plants (Mitchell et al. 1970, Grove et al. 1979), these compounds were recognised as a new class of plant hormones only in the 1990 s when several genes responsible for the biosynthesis and perception of BRs were discovered. The mutations that are associated with the loss of function of these genes usually lead to growth disturbances (including short hypocotyl, dwarfing of seedlings and mature plants) or to dark green leaves (Yang et al. 2011). The ability of these compounds to

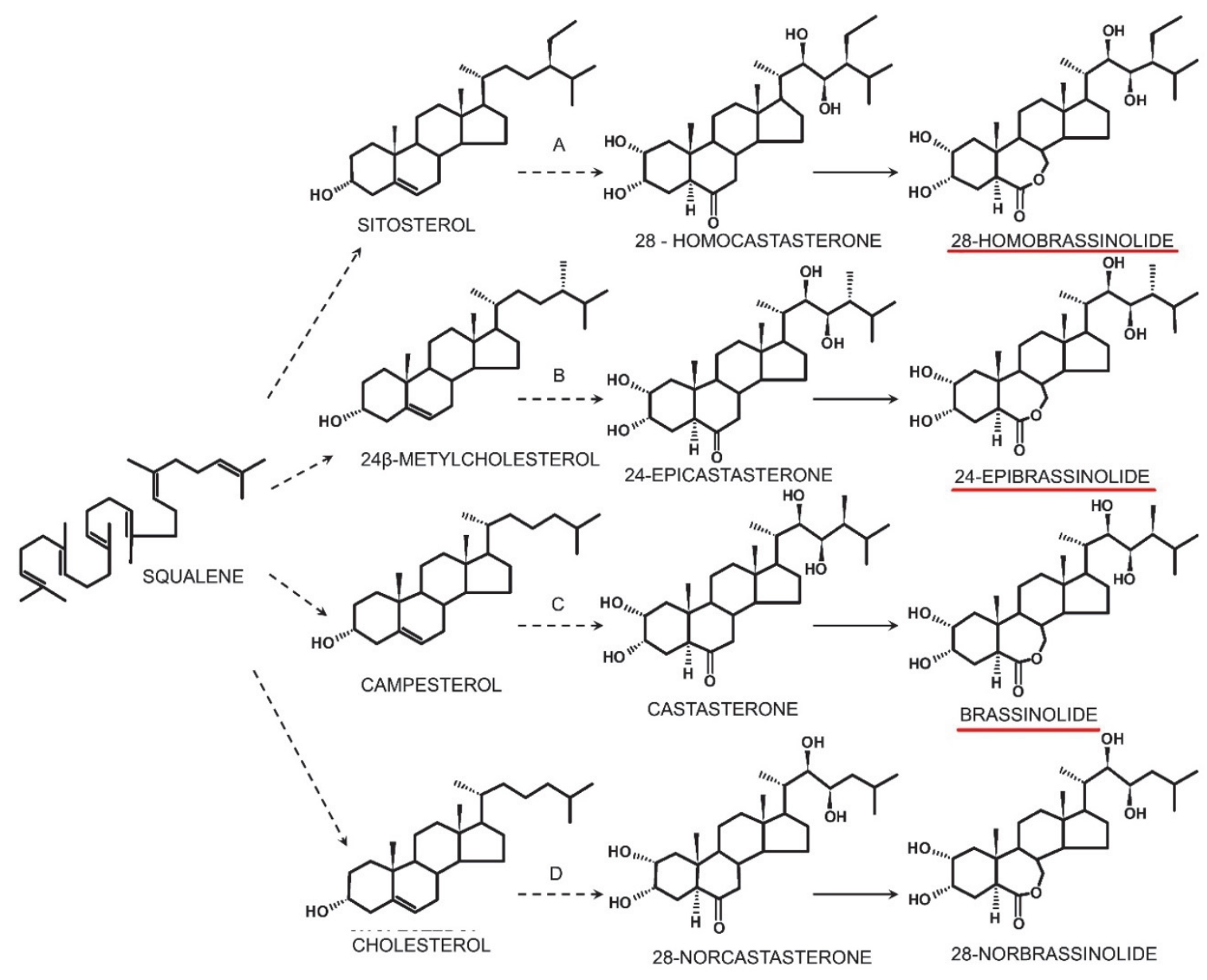

Fig. 1. Simplified model of biosynthesis of selected BRs in plants: $A$ - type $C_{29}$ (Takatsuto et al. 1999, Schaller 2003, Kim et al. 2006), $B$ and $C$ - type $C_{28}$ (B - Winter et al. 1999, Park et al. 2000, $C$ - Takatsuto et al. 1999, Park et al. 2000, Schaller 2003, Kim et al. 2004, 2006), $D$ - type $C_{27}$ (Schaller 2003, Kim et al. 2004, 2006). BRs tested in experiments with high and low temperature are underlined. 
counteract the negative effects of environmental stresses in plants should, however, be considered as a particularly interesting characteristic of BRs due to the possibility of their practical application in agriculture/horticulture (Krishna 2003, Song et al. 2016, Shu et al. 2017). During their life cycle, plants are usually exposed to different biotic and abiotic stresses, which may result in a decrease in the yield. Among the abiotic stresses, too low or too high temperatures are particularly serious problems in

\section{The structure and properties of cell membranes}

Low temperature significantly increases membrane lipid peroxidation due to the increased production of free radicals. Membrane lipid peroxidation is usually estimated based on a spectrophotometric determination of the malondialdehyde (MDA) content (the final oxidation product of polyunsaturated fatty acids) by a reaction with thiobarbituric acid (TBA), which generates a coloured TBA-MDA complex (Hodges et al. 1999). An increase in membrane lipid peroxidation was observed in tomato seedlings exposed to day/night $(\mathrm{d} / \mathrm{n})$ temperatures of $12 / 6^{\circ} \mathrm{C}$ for $12 \mathrm{~d}$ (Cui et al. 2016), as well as in tomato fruits that were stored at $1{ }^{\circ} \mathrm{C}$ for 3 weeks (Aghdam et al. 2012). Spraying of seedlings or fruits with 24-epibrassinolide prior to cold considerably decreased the MDA content compared to seedlings or fruits without BR application. A similar phenomenon was found for the fruits of pepper, eggplant seedlings, and cucumber plants (Hu et al. 2010, Wang et al. 2012, Jiang et al. 2013, Wu et al. 2014a). Moreover, cell suspensions of Chorispora bungeana that were cultured with 24-epibrassinolide $\left(0.05 \mathrm{mg} \mathrm{dm}^{-3}\right.$ or $\left.0.1 \mu \mathrm{M}\right)$ showed a marked decrease (by 20 to $40 \%$ ) of MDA content compared to the culture that was grown at $0-4{ }^{\circ} \mathrm{C}$ (for $3-5 \mathrm{~d}$ ) but without 24-epibrassinolide (Liu et al. 2009, 2011). The participation of BRs in membrane protection against peroxidation in cold was confirmed by studies on BR mutants. $\mathrm{Qu}$ et al. (2011) applied $0{ }^{\circ} \mathrm{C}(24 \mathrm{~h})$ to A. thaliana plants and found that the bri1-116 (-/-) mutant (BR insensitive null allele of the BR receptor BRI1) reached significantly higher MDA content than the Col-0 wild type. Finally, in tomatoes with a partial deficiency of BRs that were exposed to cold, membrane lipid peroxidation was increased while the overexpression of the BR biosynthetic gene Dwarf or the application of 24epibrassinolide reduced the cold-induced oxidative damage (Xia et al. 2017).

In addition to MDA accumulation, ion leakage measurement can be used, which indicates cell membrane permeability. Increased ion leakage is usually interpreted as membrane damage. In the primary leaves of oilseed rape kept at $2{ }^{\circ} \mathrm{C}, 24$-epibrassinolide $(0.05$ and $1 \mu \mathrm{M})$ decreased ion leakage (by about $80 \%$ ) compared to the control (Janeczko et al. 2007). The authors noted temperature-, tissue-, and concentration-dependent effects agriculture and horticulture. Species, such as cucumbers, tomatoes, or maize are very sensitive to cold, while frost, especially when occurs under insufficient snow cover on fields, can cause significant yield losses of winter crops, e.g., oilseed rape or cereals. High temperature, in turn, is particularly dangerous to plants when combined with drought. Table 1 Suppl. summarises the data for the temperature ranges, species, and brassinosteroids that were used in order to ameliorate the plant damage. of BRs on this parameter. Mango fruits that are stored at $5{ }^{\circ} \mathrm{C}$ for $28 \mathrm{~d}$ have electrolyte leakage about $40 \%$, but BR treatment $(10 \mu \mathrm{M})$ prior to storage reduced this value to $20 \%$ ( $\mathrm{Li}$ et al. 2012). In tomato fruits, stored at $1{ }^{\circ} \mathrm{C}$ for three weeks, electrolyte leakage was approximately $85 \%$, whereas this value was decreased to $70 \%$ in fruits that were treated with $3 \mu \mathrm{M}$ brassinolide (Aghdam et al. 2012). A cell suspension of $C$. bungeana cultured at 0 and $4{ }^{\circ} \mathrm{C}(3 \mathrm{~d})$ with 24-epibrassinolide $(0.1 \mu \mathrm{M})$ had approximately a $20 \%$ lower ion leakage compared to the stressed cultures without hormone (Liu et al. 2011). Qu et al. (2011) applied $0{ }^{\circ} \mathrm{C}$ for $24 \mathrm{~h}$ to A. thaliana plants and found that the bril-116 (-/-) mutant reached approximately $50 \%$ higher ion leakage than the Col-0 wild type. Eremina et al. (2016) measured electrolyte leakage in cold-acclimated and frozen leaves of A. thaliana wild type and two mutants: BR-hypersignalling line (BRI1oe) and BR-signalling defective mutants (bri1-301). After freezing at $-10{ }^{\circ} \mathrm{C}(6 \mathrm{~h})$, BRIloe had a lower (by about $20 \%$ ) whereas bril-301 had a higher (by about $20 \%$ ) electrolyte leakage in comparison to the wild type.

Typically, during the process of acclimation to low temperature, membrane structural changes aim at the increasing proportion of unsaturated fatty acids, which improves the fluidity of the membranes. Brassinosteroids may affect the fatty acid composition of cell membranes. An increase in content of unsaturated fatty acids, linoleic acid $\mathrm{C} 18: 2$ and linolenic acid $\mathrm{C} 18: 3$, in mango fruits that were treated with brassinolide and stored at $5{ }^{\circ} \mathrm{C}$ was higher than in the control. Simultaneously, the content of palmitic acid $\mathrm{C} 16: 0$, palmitoleic acid $\mathrm{C} 16: 1$, stearic acid C18:0, and oleate acid C18:1 was slightly reduced by BR (Li et al. 2012). In monogalactosyldiacylglycerols (MGDG), a fraction that was isolated from a winter oilseed rape green callus acclimated at $2{ }^{\circ} \mathrm{C}, 24$-epibrassinolide decreased the molar percentage of saturated fatty acids and increased the percentage of unsaturated fatty acids $(18: 1,18: 2$, and 18:3) compared to a callus grown in the cold without BR (Janeczko et al. 2009). The MGDG fraction (next to the fraction of digalactosyldiacylglycerols) is considered to be abundant especially in the thylakoid membranes (Johnson and Williams 1989). 
Li et al. (2012), analysed the plasma membranes of mango fruits that were stored at $5{ }^{\circ} \mathrm{C}$ for $28 \mathrm{~d}$ by measuring the phase transition temperature using differential scanning calorimetry (DSC) and polar lipid fluidity by electron paramagnetic resonance (EPR). The phase transition temperature in the fruits that are not treated with brassinolide is constant and about $6.5{ }^{\circ} \mathrm{C}$ during the storage period, while phase transition temperature in brassinolide-treated plants is markedly decreased. Polar lipid fluidity is determined on the basis of the EPR spectra, which enable the order parameter (S) and rotational correlation time $\left(\tau_{\mathrm{c}}\right.$; inversely proportional to membrane fluidity) to be calculated. A gradual increase in the value of both parameters is observed with storage time in brassinolide-untreated plants, and there is a decrease in $S$ and $\tau_{c}$ in plants to which this BR was applied. This indicates increased membrane fluidity in the presence of brassinolide. These results correspond to last studies, which were done using a Langmuir bath by Filek et al. (2017). When 24-epibrassinolide and 24-epicastasterone are introduced into lipid monolayers, their physicochemical properties changed. Lipids for monolayer formation were isolated from the leaves of wheat growing at 5 and $20{ }^{\circ} \mathrm{C}$ and 24-epibrassinolide incorporation into lipid monolayer resulted in the formation of more flexible surface structures (Filek et al. 2017). However, 24-epicastasterone induced the opposite effect. These results show importance of the chemical structure of BRs for their interaction with membranes.

High temperature also increases lipid peroxidation. In melon seedlings, a d/n temperature of $42 / 32{ }^{\circ} \mathrm{C}$ for $2 \mathrm{~d}$ increased the MDA content compared to the control (Zhang et al. 2014). Pretreatment with 24-epibrassinolide $\left(1 \mathrm{mg} \mathrm{dm}{ }^{-3}\right)$ reduced MDA accumulation by $35 \%$. A similar effect was observed in rice plants grown at high $\mathrm{d} / \mathrm{n}$ temperatures of $40 / 30{ }^{\circ} \mathrm{C}$ for $7 \mathrm{~d}$ (Thussagunpanit et al. 2015b). In eggplants at $\mathrm{d} / \mathrm{n}$ temperatures of $43 / 38{ }^{\circ} \mathrm{C}(8 \mathrm{~d}), 0.1 \mu \mathrm{M}$ 24-epibrassinolide reduced the MDA content by $16 \%$ compared to plants that were not treated (Wu et al. 2014b). Mazorra et al. (2011) studied

\section{Mobilization of cellular antioxidant system}

Low temperature: A temperature that is too low for optimal growth is accompanied by increased free radical formation $\left(\mathrm{H}_{2} \mathrm{O}_{2}, \mathrm{O}_{2}{ }^{\bullet-}\right.$, and $\left.{ }^{\bullet} \mathrm{OH}\right)$ in cells, which is associated with the activation of the antioxidant system. The antioxidant system consists of enzymatic antioxidants such as superoxide dismutase (SOD), catalase (CAT), peroxidase (POD), and non-enzymatic antioxidants, including ascorbic acid (AsA) or tocopherols (Liu et al. 2009, 2011, Hu et al. 2010, Jiang et al. 2013, Cui et al. 2016). In eggplant seedlings, d/n temperatures of $10 / 5$ for $8 \mathrm{~d}$ increased SOD, POD, ascorbate peroxidase (APX), and CAT activities $(\mathrm{Wu}$ the effect of $45^{\circ} \mathrm{C}(4-8 \mathrm{~h})$, on tomato plants (wild type and brassinosteroid mutants (mutant with altered BRs sensitivity curl3-abs, extremely dwarf mutant $d^{x}$ and dwarf-overexpressing line 35SD). An increase in MDA content was found after $7 \mathrm{~d}$ of recovery from heat stress in the $\mathrm{Wt}, \mathrm{d}^{\mathrm{x}}, 35 \mathrm{SD}$ and curl3 $^{-a b s}$ plants but 24-epibrassinolide $(1 \mu \mathrm{M})$ reduced the MDA content.

Concluding remarks: Cell membranes may act as "thermal sensors", which is the primary cause of many other metabolic changes within a cell including the expression of certain genes (Horvath et al. 2012). From this point of view, the ability of BRs to induce structural/functional changes in the cell membrane is interesting. Based on presented knowledge, various possible directions of BR action on a membrane can be noted. The first is the influence of BRs on the fatty acid composition towards an increased proportion of unsaturated fatty acids. This suggests the involvement of BRs in the biosynthesis of fatty acids or fatty acid transport and incorporation into cell membranes. Secondly, BRs (similarly as some other sterols) may enter cell membrane directly and modify its properties through, for example, increasing the distance between fatty acid chains, which also may improve the functioning of the membrane under unfavourable temperature conditions. Another mechanism of BR action could be its indirect effect on the inactivation of the excess of reactive oxygen species (ROS) that are generated under stress conditions (see next chapter). ROS-induced damage of constituent membrane elements is manifested, as is mentioned above, by the accumulation of the products of lipid peroxidation. BR-stimulated deactivation of free radicals probably indirectly protects cell membranes and thus lowers lipid peroxidation. A separate issue is the fact that important functional proteins such as water transporting channels and proton pumps are present in the cell membranes. Knowledge of the effect of BR on membrane proteins is rudimentary (Morillon et al. 2001, Yang et al. 2003) and especially requires studies for low or high temperature conditions.

et al. 2014a). The application of $0.1 \mu \mathrm{M}$ 24-epibrassinolide prior to cold, additionally stimulated the activity of these enzymes, by $31,120,33$, and $64 \%$, respectively. Treatment of pepper fruits with $15 \mu \mathrm{M}$ 24-epibrassinolide caused higher CAT and glutathione reductase (GR) activities during storage at $3{ }^{\circ} \mathrm{C}$ for $18 \mathrm{~d}$ (Wang et al. 2012). Further, the application of 24-epibrassinolide to two cold-exposed tomato cultivars (tolerant Zhongza9 and sensitive Zhongshu4) increased SOD, POD, and CAT activities by about $50 \%$ (Cui et al. 2016). In coldexposed cucumber plants, 28-homo-brassinolide and 24-epibrassinolide stimulated SOD activity ( $\mathrm{Hu}$ et al. 
2010, Farriduddin et al. 2011) and Jiang et al. (2013) emphasised the significant role of irradiance for post-cold plant regeneration and brassinosteroid action. Cucumber plants were exposed to cold $\left(10 / 7{ }^{\circ} \mathrm{C}, 6 \mathrm{~d}\right)$, and then they were regenerated $4 \mathrm{~d}$ under high $\left(600 \mu \mathrm{mol} \mathrm{m} \mathrm{m}^{-2} \mathrm{~s}^{-1}\right)$ and low $\left(100 \mu \mathrm{mol} \mathrm{m} \mathrm{m}^{-2} \mathrm{~s}^{-1}\right)$ irradiance. Plants that were treated with $0.1 \mu \mathrm{M}$ 24-epibrassinolide (spraying on day 5 of cold) and recovered at a high irradiance demonstrated a marked increase in the activities of SOD, APX, monodehydroascorbate reductase (MDAR), dehydroascorbate reductase (DHAR), and GR as well as a reduced glutathione/oxidised glutathione (GSH/GSSG) ratio and ascorbate/dehydroascorbate (AsA/DHA) ratio. The plants that recovered under low irradiance had only a slightly higher SOD activity. Finally, the most recent studies of Xia et al. (2017) shows that in tomato, BR increases the accumulation of the transcripts of respiratory burst oxidase homolog1 $(R B O H 1)$ and glutaredoxin $(G R X)$ genes, and that BR-induced cold tolerance is accompanied by a higher ratio of reduced/oxidised 2-cysteine peroxiredoxin (2-Cys Prx) and the activation of antioxidant enzymes. The authors suggested that in tomato, BRs enhance cold tolerance through a signalling cascade that involves RBOH1, GRXs, and 2-Cys Prx.

The effect of BRs on antioxidant enzyme activities has also been confirmed in cell suspensions. The application of 24-epibrassinolide $(0.1 \mu \mathrm{M})$ to C. bungeana cell cultures grown at 0 and $4{ }^{\circ} \mathrm{C}$ for 3 or 5 $\mathrm{d}$ resulted in additional stimulation of the APX, CAT, GR, POD and SOD activities and increase in AsA and GSH content compared to the cell cultures without the added hormone (Liu et al. 2009, 2011).

High temperature: The stress caused by a high temperature also activates the antioxidant system. Wu et al. (2014b) studied eggplants in the five-leaf stage subjected to high $\mathrm{d} / \mathrm{n}$ temperatures of $43 / 38{ }^{\circ} \mathrm{C}$ for $8 \mathrm{~d}$ and they found a significant increase in the activities of SOD, POD, CAT, and APX by 35, 37, 26, and $14 \%$, respectively, as well as the AsA and GSH content (by 28 and $25 \%$, respectively) compared to plants that were not exposed to high temperature. The plants that were previously treated with $0.1 \mu \mathrm{M}$ 24-epibrassinolide showed increased SOD, POD, CAT, and APX activities by $30,103,68$, and $22 \%$, respectively, compared to the plants that were exposed to a high temperature without BR treatment. A marked increase in the AsA and GSH content (48 and $27 \%$, respectively) was also observed in BR-treated plants compared to stressed, but not BRtreated plants. High temperatures $\left(42 / 32{ }^{\circ} \mathrm{C}, 2 \mathrm{~d}\right)$ stimulated the activity of SOD, POD, CAT, and APX in melon (Zhang et al. 2014). In this case, 24-epibrassinolide $\left(1 \mathrm{mg} \mathrm{dm}^{-3}\right)$ pre-treatment further enhanced SOD, POD, CAT and APX activities. 24-Epibrassinolide also alleviated the high temperature-induced oxidative stress by increasing the enzymatic and non-enzymatic antioxidant and glyoxalase systems in seedlings of Ficus concinna (Jin et al. 2015). On the other hand, no effect of 24-epibrassinolide $(1 \mu \mathrm{M})$ on the activity of antioxidative enzymes was observed in heat-exposed tomatoes (Mazorra et al. 2011), which suggests that the effect of BRs may be species or cultivar dependent.

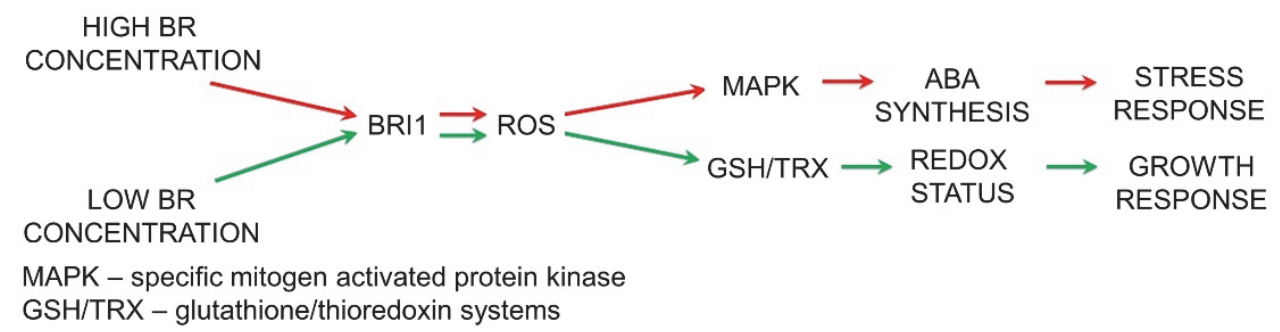

Fig. 2. BR concentration-dependent model of growth and the stress response of plants - role of ROS (modified from Xia et al. (2015).

Concluding remarks: According to the best of our knowledge, there is lack of data showing the genetic background of the impact of BR on the antioxidant system under high or low temperature. The results described by Xia et al. (2009a) for cucumbers grown under optimal conditions suggest that one of the possible reasons why the activity of antioxidant enzymes increases in the presence of BRs may be higher expressions of the genes coding these enzymes. Xia et al. (2009a) also noticed that cucumber plants treated with 24epibrassinolide $(0.1 \mu \mathrm{M})$ have higher relative abundance of $C A T, P O D$, and $M D A R$ transcripts than plants that were not treated with BRs. According to many researchers, reactive oxygen species (ROS), in addition to the damaging action on cellular components and structures, also play a signalling role (Kreslavski et al. 2012). The concept of BR action on the antioxidant cell system proposed by Xia et al. $(2009 \mathrm{a}, 2015)$ is interesting in this context (Fig. 2). BR receptor activation (as a result of ligand-receptor binding) leads to the production of ROS, e.g. $\mathrm{H}_{2} \mathrm{O}_{2}$, however, spatial and temporal changes in the ROS content depend on the BR content in the tissues. Low BR content can cause a temporary increase in ROS, which stimulates the cell antioxidant system. This leads to a shift in the cell redox balance towards reducing processes and acts as a signal, e.g. stimulating photosynthesis and developmental processes. A high BR content in the tissues results in long-term ROS 
accumulation, which in turn induces a phosphorylation cascade of mitogen-activated protein kinase. In this case, ROS and kinase stimulate the biosynthesis of abscisic acid, which is the main hormone associated with stress tolerance. In this context, the increased accumulation of BRs as a result of low or high temperature is worth noting (Dockter et al. 2014, Pociecha et al. 2016). Dockter et al. (2014) found that the content of castasterone during the growth of barley is $7.43 \mathrm{pmol} \mathrm{g}^{-1}$ (f.m.) at $14{ }^{\circ} \mathrm{C}$, but it increased to $10.31 \mathrm{pmol} \mathrm{g}^{-1}$ (f.m.) in plants grown at $26{ }^{\circ} \mathrm{C}$. In turn, Pociecha et al. (2016) showed that the castasterone content in rye grown at $18{ }^{\circ} \mathrm{C}$ is 4 - 5 pmol g-1(f.m.), however, as a result of six weeks of cold, this content increases to about 14 - 16 pmol g$^{-1}$ (f.m.). This phenomenon can result in the activation of mechanism where ABA is involved (proposed by Xia et al. 2015; Fig. 2). On the other hand, BR supply may also slightly increase ROS production even before the onset of stress, which results in a higher antioxidant system activity. The increased activity of antioxidant system in non-stressed plants that were treated with BRs was also reported by Jiang et al. (2013).

\section{Photosynthetic pigments}

Low temperature: One of the most important symptoms of stress that is caused by a low temperature is a decrease in the content of photosynthetic pigments. Soaking pepper fruits in brassinolide solutions $(5,10$, and $15 \mu \mathrm{M})$ increases the chlorophyll content by 23,17 , and $24 \%$, respectively, on the $18^{\text {th }}$ day of storage at $3{ }^{\circ} \mathrm{C}$, compared to plants that were not treated with BR (Wang et al. 2012). The senescence of cut leaves of oilseed rape is accelerated at $2{ }^{\circ} \mathrm{C}$, but leaf infiltration with 24-epibrassinolide $(0.001-1 \mu \mathrm{M})$ significantly reduces this phenomenon (Janeczko et al. 2007). In 30-d-old cucumber plants, a $40 \%$ reduction in the chlorophyll content after $18 \mathrm{~h}$ at $3-5{ }^{\circ} \mathrm{C}$ was limited to only $16 \%$ after pretreatment with 28 -homobrassinolide $\left(10^{-8} \mathrm{M}\right)$ (Farriduddin et al. 2011). In eggplant seedlings, the content of chlorophyll $a, b$, and $(a+b)$ decreased by 32 , 57 , and $39 \%$, respectively, during $8 \mathrm{~d}$ at $10 / 5{ }^{\circ} \mathrm{C}$ and 24-epibrassinolide $(0.05-0.2 \mu \mathrm{M})$ alleviated this detrimental effects of cold (Wu et al. 2014a). He et al. (1991) observed that brassinolide improves the greening of etiolated leaves in maize exposed to cold.

High temperature: Stress caused by a high temperature is also accompanied with a decrease in chlorophyll content. In eggplant seedlings exposed to $43 / 38{ }^{\circ} \mathrm{C}$ for 8 $\mathrm{d}$, pretreatment with $0.1 \mu \mathrm{M}$ 24-epibrassinolide increased the content of chlorophyll $a, b$, and $(a+b)$ by 17,27 , and $20 \%$, respectively, compared to heat-exposed plants that were not BR-treated (Wu et al. 2014b). The decrease in chlorophyll content was milder in rice supplemented with 24-epibrassinolide prior to exposure to $40 / 30{ }^{\circ} \mathrm{C}$ for $7 \mathrm{~d}$ relative to the control (Thussagunpanit et al. 2015a). In another study, this rice cultivar treated with 24-epibrassinolide showed an increase in the content of chlorophyll $a$, $b$, and $(a+b)$ and carotenoids by $86,74,83$, and $28 \%$, respectively, on the $7^{\text {th }}$ day of a high temperature exposure, compared to plants that were not treated with BR (Thussagunpanit et al. 2015 b). In the plants that are treated with 24-epibrassinolide, the content of individual pigments achieved after 7-d recovery the level of the plants that are not exposed to heat. In maize growing in a net house with maximum temperature of $17.6-24.5{ }^{\circ} \mathrm{C}$ and minimum temperature of $2.8-7.4{ }^{\circ} \mathrm{C}(21 \mathrm{~d})$, decrease in the chlorophyll content is milder when the seedlings are supplemented with $1 \mu \mathrm{M}$ 24-epibrassinolide (Singh et al. 2012). 24-Epibrassinolide also ameliorates photosynthetic pigment losses in melon seedlings exposed to $42 / 32{ }^{\circ} \mathrm{C}$ for $2 \mathrm{~d}$ in the stage of 3 - 4 leaves (Zhang et al. 2014).

Concluding remarks: Considering the fact that chlorophyll degradation occurs in plants under stress (Sakuraba et al. 2014), it can be assumed that BRs restrict this process. Presumably, BRs affect the synthesis or activity of the enzymes that participate in the processes of chlorophyll breakdown such as $\mathrm{Chl} b$ reductase (Hörtensteiner and Kräutler 2011). BRs may also participate in regulating chlorophyll biosynthesis. BR-deficient barley mutants at the optimal temperature accumulated a few percent less of chlorophylls compared to wild type (Janeczko et al. 2016). Simultaneously, the mutants also had lower content of cytokinins, which are stimulators of chloroplast development and chlorophyll biosynthesis (Parthier 1979). This may suggest an indirect effect of BRs on chlorophyll biosynthesis through cytokinin action. The engagement of BR signalling in chlorophyll accumulation is also suggested by Yoshizawa et al. (2014). All of these hypotheses require verification in plants that are exposed to low/high temperatures.

\section{Gas exchange, photosystem activities, and $\mathrm{CO}_{2}$ assimilation}

Low temperature: Gas exchange parameters are very susceptible to environmental changes. In cucumber plants, 28-homobrassinolide $\left(10^{-8} \mathrm{M}\right)$ and 24-epibrassinolide $\left(0.1 \mathrm{mg} \mathrm{dm}^{-3}\right)$ reduce the cold-induced decreases in 
net photosynthetic rate $\left(\mathrm{P}_{\mathrm{N}}\right)$, stomatal conductance $\left(\mathrm{g}_{\mathrm{s}}\right)$, internal carbon dioxide concentration $\left(\mathrm{c}_{\mathrm{i}}\right)$, and transpiration rate (E) (Hu et al. 2010, Farriduddin et al. 2011). The effect is confirmed by the 24-epibrassinolide treated eggplants exposed to $10 / 5^{\circ} \mathrm{C}$ for $8 \mathrm{~d}$ (Wu et al. 2014a).

Low temperature usually decreases the efficiency of the photosystems (PS). Fluorescence methods permit a detailed characterization of any disturbances in the energy flow especially within PS II. Cucumber plants in the 3-leaf stage that were sprayed with 24-epibrassinolide $\left(0.1 \mathrm{mg} \mathrm{dm}^{-3}\right)$ prior to exposure to $12 / 8{ }^{\circ} \mathrm{C}$ for $3 \mathrm{~d}$ reached higher values of the effective quantum yield of PS II photochemistry $\left(\Phi_{\mathrm{PSII}}\right)$ and photochemical quenching coefficient $\left(\mathrm{q}_{\mathrm{P}}\right)$ and lower nonphotochemical quenching (NPQ) than plants that were not sprayed (Hu et al. 2010). The beneficial effect of this hormone on the efficiency of PS II was also observed during the post-stress regeneration ( $\mathrm{Hu}$ et al. 2010). After the treatment of 28-homobrassinolide $\left(10^{-8} \mathrm{M}\right), 30$-d-old cucumber plants reached higher values of PS II maximum quantum yield (variable to maximum fluorescence ratio, $\mathrm{F}_{\mathrm{v}} / \mathrm{F}_{\mathrm{m}}$ ) under cold $\left(3-5^{\circ} \mathrm{C}, 18 \mathrm{~h}\right)$ compared to plants without the BR (Farriduddin et al. 2011). Further, the $\mathrm{F}_{\mathrm{v}} / \mathrm{F}_{\mathrm{m}}$ ratio in cucumber was restored to the level before cold by applying 24-epibrassinolide on the $5^{\text {th }}$ day of cold (at $10 / 7{ }^{\circ} \mathrm{C}$ for $6 \mathrm{~d})$, but only under high irradiance $\left(600 \mu \mathrm{mol} \mathrm{m} \mathrm{m}^{-2} \mathrm{~s}^{-1}\right)$ (Jiang et al. 2013). No effect of BR on PS I efficiency was observed in this case. In seedlings of eggplant exposed to $10 / 5{ }^{\circ} \mathrm{C}$ for $8 \mathrm{~d}$, the values of $\mathrm{F}_{\mathrm{v}} / \mathrm{F}_{\mathrm{m}}$, potential photochemical efficiency $\left(\mathrm{F}_{\mathrm{v}} / \mathrm{F}_{0}\right), \Phi_{\text {PSII }}$, excitation energy capture efficiency of open centres $\left(\mathrm{F}_{\mathrm{v}}{ }^{\prime} / \mathrm{F}_{\mathrm{m}}{ }^{\prime}\right)$, and $\mathrm{qP}$ decreased by $9,32,17,9$, and $14 \%$, respectively, and 24-epibrassinolide $(0.05 \quad-0.20 \quad \mu \mathrm{M})$ significantly counteracted this phenomenon (Wu et al. 2014a). Finally, in cold-treated tomato plants, with a partial deficiency in BRs, $F_{v} / F_{m}$ is decreased (Xia et al. 2017). Overexpression of the BR biosynthetic gene Dwarf or the application of 24-epibrassinolide increased the $\mathrm{F}_{\mathrm{v}} / \mathrm{F}_{\mathrm{m}}$ under cold (Xia et al. 2017).

Under cold, BRs stimulated activity of enzymes responsible for various stages of carbon dioxide binding. The activity of carbonic anhydrase (CA), which participates in the transport of inorganic carbon (Henry 1996), decreased by $24 \%$ in cucumber plants under cold but did not change in plants that were sprayed with 28-homobrassinolide $\left(10^{-8} \mathrm{M}\right)$ prior to cold (Farriduddin et al. 2011). Research conducted by Jiang et al. (2013) on cucumber plants exposed to $10 / 7^{\circ} \mathrm{C}$ for $6 \mathrm{~d}$ showed that $\mathrm{BR}$ play a role in regulating $\mathrm{CO}_{2}$ binding by ribulose-bisphosphate carboxylase/oxygenase (Rubisco). Plants that were sprayed with 24-epibrassinolide prior to cold treatment and recovered under irradiance of $600 \mu \mathrm{mol} \mathrm{m} \mathrm{m}^{-2} \mathrm{~s}^{-1}$ reached a significantly higher Rubisco content, total Rubisco activity, and Rubisco activase (RCA) activity compared to the stressed plants that were not sprayed. This phenomenon did not occur during recovery under irradiance of $100 \mu \mathrm{mol} \mathrm{m} \mathrm{m}^{-2} \mathrm{~s}^{-1}$. An increase in Rubisco activity after 24-epibrassinolide application was also confirmed by Pociecha et al. (2016) in a study on winter rye plants exposed to 3 and 6 weeks of cold. On the other hand, in perennial ryegrass, when 24-epibrassinolide $\left(0.25 \mathrm{mg} \mathrm{dm}^{-3}\right)$ was applied before plant exposure to $4{ }^{\circ} \mathrm{C}$ for 6 weeks, the Rubisco activity was reduced by about $30 \%$ but only in sensitive cv. Amarant and not in the resistant cv. Flinston (Pociecha et al. 2017). This suggests that the effect of BRs on Rubisco activity in cold may be cultivar dependent.

High temperature: In rice, 24-epibrassinolide limited heat-induced $\left(40 / 30{ }^{\circ} \mathrm{C}, 7 \mathrm{~d}\right)$ disturbances of gas exchange. A significant increase was recorded in $\mathrm{P}_{\mathrm{N}}, \mathrm{g}_{\mathrm{s}}$, and $\mathrm{E}$ by 325,240 , and $235 \%$, respectively and a decrease in internal $\mathrm{CO}_{2}$ concentration $\left(\mathrm{c}_{\mathrm{i}}\right)$ by $97 \%$ in plants treated with 24-epibrassinolide compared to nontreated and heat-exposed plants (Thussagunpanit et al. $2015 a, b)$. Positive effect of 24-epibrassinolide (0.005 $0.20 \mu \mathrm{M})$ on the gas exchange in eggplants subjected to $43 / 38^{\circ} \mathrm{C}(8 \mathrm{~d})$ was also observed by Wu et al. (2014b). In melon plants exposed to $42 / 32{ }^{\circ} \mathrm{C}(2 \mathrm{~d})$, spraying with 24-epibrassi-nolide ( 1 and $1.5 \mathrm{mg} \mathrm{dm}^{-3}$ ) maintained $\mathrm{P}_{\mathrm{N}}$ and $\mathrm{g}_{\mathrm{s}}$ on a level close to those at $30 / 20{ }^{\circ} \mathrm{C}$ (Zhang et al. 2014). High temperature tolerant and sensitive cultivars of melon grown at $42 / 32{ }^{\circ} \mathrm{C}$ for $2 \mathrm{~d}$ also had an improved $\mathrm{P}_{\mathrm{N}}$ and higher values of $\mathrm{F}_{\mathrm{v}} / \mathrm{F}_{\mathrm{m}}, \mathrm{F}_{\mathrm{v}}{ }^{\prime} / \mathrm{F}_{\mathrm{m}}{ }^{\prime}, \Phi_{\mathrm{PSII}}$, and $\mathrm{qP}$ and lower values of $\mathrm{F}_{0}$ and NPQ after 24-epibrassinolide treatment (Zhang et al. 2013, 2014). The decrease in PS II effectivness caused by temperature $43 / 38{ }^{\circ} \mathrm{C}(8 \mathrm{~d})$ in eggplant seedlings was compensated by 24 -epibrassinolide $(0.05-0.2 \mu \mathrm{M})(\mathrm{Wu}$ et al. 2014b). In rice, 24-epibrassinolide also effectively alleviated the negative effects of $40 / 30{ }^{\circ} \mathrm{C}(7 \mathrm{~d})$ on PS II (Thussagunpanit et al. $2015 \mathrm{a}, \mathrm{b})$. The minimum fluorescence $\left(\mathrm{F}_{0}\right)$ was lower in plants that were sprayed with 24-epibrassinolide before stress, and parameters such as $\mathrm{F}_{\mathrm{m}}, \mathrm{F}_{\mathrm{v}} / \mathrm{F}_{\mathrm{m}}, \mathrm{F}_{\mathrm{v}}{ }^{\prime} / \mathrm{F}_{\mathrm{m}}$ ' had higher values than those noted in the stressed plants without BR application. The electron transport rate (ETR) in plants treated with 24-epibrassinolide was also significantly improved (Thussagunpanit et al. 2015a). An analysis of chlorophyll $a$ fast fluorescence kinetics in spring barley exposed to $42{ }^{\circ} \mathrm{C}(3 \mathrm{~h})$ indicated an abnormal energy flow in PS II that was manifested in a decrease in energy absorption (ABS/CSm), energy flux for trapping (TRo/CSm), and energy flux for electron transport (ETo/CSm) (Janeczko et al. 2011). The protective effect of 24-epibrassinolide $\left(0.25 \mathrm{mg} \mathrm{dm}^{-3}\right.$, leaf infiltration before heat) was observed in the first leaf. $\mathrm{ABS} / \mathrm{CSm}, \mathrm{TRo} / \mathrm{CSm}$, and ETo/CSm values were higher by approximately 23, 49, and $69 \%$, respectively, compared to the values noted in the stressed plants that were not treated with BR. Xia et al. (2009a) noticed that after cold $\left(8^{\circ} \mathrm{C}\right)$, cucumber plants that were treated with 24-epibrassinolide had higher values of ETR than untreated plants. Application of BR biosynthesis inhibitor brassinazole (Brz) lowered ETR values below the control 
values while treatment of plants with combination of Brz +24 -epi-brassinolide restored the values to the control level.

Concluding remarks: $\mathrm{BRs}$ regulate gas exchange in plants exposed to low/high temperatures. Improved $\mathrm{P}_{\mathrm{N}}$ is often connected with stimulation of the activity of the enzymatic system. Rubisco activity is lower in BR-deficient mutants of barley (under optimal conditions) which may confirm regulatory role of BRs in functioning of the enzyme (Janeczko et al. 2016). The BR-stimulated accumulation of the transcripts of genes encoding Rubisco or RCA (Xia et al. 2009a,b) was also observed. Xia et al. (2009b) showed that BR promotes but Brz inhibits expression of genes encoding the Calvin cycle enzymes required for Rubisco regeneration. All of the described molecular mechanisms of BR action should be confirmed for plants that are cultured at low/high temperature. The simplest reason for the decreased efficiency of PS II during plant exposure to high/low temperatures seems to be a reduced content of photosynthetic pigments (described above). Further, the correct structure and functioning of the thylakoid membranes, where electron carriers are located, is essential to maintain high PS efficiency. The stabilising effect of BRs on the structure and properties of the membranes at low/high temperatures is mentioned in another chapter. Although microscopic analyses show that the application of 24-epibrassinolide maintains the typical shape of the chloroplasts and promotes the formation of grana in the stressed plants, more detailed studies of the effect of BR on photosynthetic light reactions in plants growing at low/high temperature should be done, especially using BR-biosynthesis or signalling mutants. The positive impact of BRs on the thylakoid membranes and chloroplast ultrastructure was confirmed in salt-stressed cucumber plants (Yuan et al. 2012). Finally, BRs may also have an indirect influence on $\mathrm{CO}_{2}$ assimilation by improving plant water management, even if values of $\mathrm{E}$ and $\mathrm{g}_{\mathrm{s}}$ are usually higher in the BR-treated plants grown under both low or high temperatures.

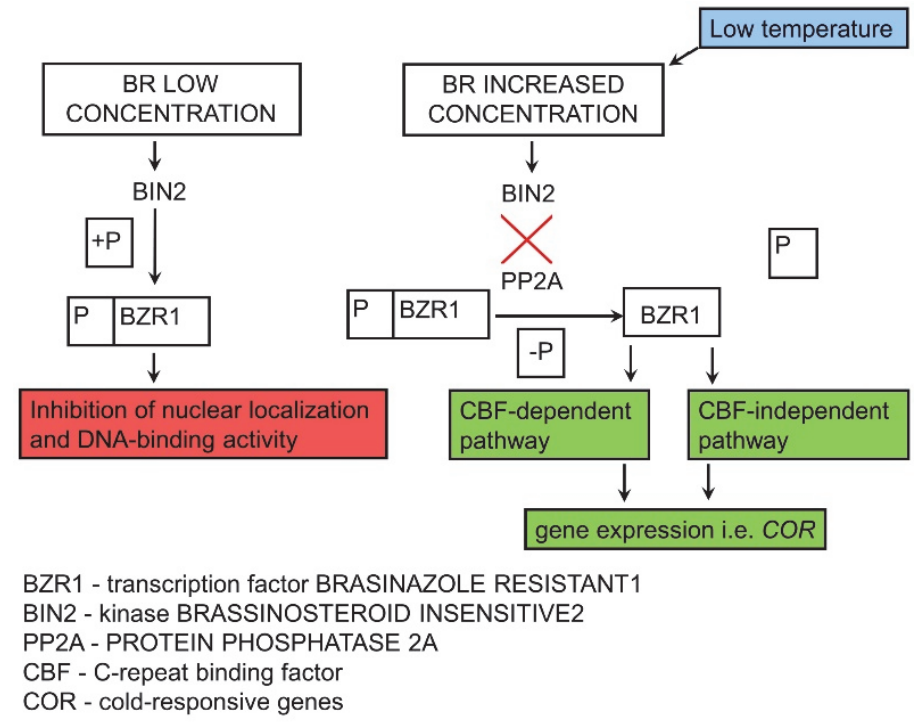

Fig. 3. A model of plant response to low temperature and low [4 - 5 pmol g-1 (f.m.)] or increased [14 - 16 pmol g-1 (f.m.)] BR concentration (modified from Wang et al. 2014 and Li et al. 2017). Brassinosteroid concentrations are exemplary given for rye based on Pociecha et al. (2016); P - phosphate. $+\mathrm{P}$ - phosphorylation, -P - dephosphorylation, $\mathrm{P}$ - phosphate attached to the protein or not attached to protein. The dephosphorylation step of BZR1 is blocked by BIN2 in the case of low BR concentration (Wang et al. 2014). A higher content of BRs allows the inactivation of BIN2 and the dephosphorylation of BZR1, which in turn can directly activate BR-responsive genes or act indirectly in a CBF-dependent way (Wang et al. 2014, Li et al. 2017). For more detail see chapter "Biosynthesis of proteins and accumulation of proline and glycinebetaine".

\section{Sugar accumulation}

Low temperature. An increase in sucrose content under cold is especially important for winter plants where it is a part of the hardening before frost. In perennial ryegrass, after pretreatment with 24-epibrassinolide $\left(0.25 \mathrm{mg} \mathrm{dm}^{-3}\right)$ and cold acclimation at $4{ }^{\circ} \mathrm{C}$ for 6 weeks, Pociecha et al. (2017) observed a significant decrease of glucose and fructose content (in cv. Amarant by about 38 and $41 \%$ and in cv. Flinston by about 28 and $63 \%$, respectively) compared to untreated plants. It is important that this effect was accompanied by an increase in content of sucrose (54 to $77 \%$ ) and also of protective sugars nystose and 1-kestose in both cultivars. The picture was not so 
clear in winter rye plants that were grown at $4{ }^{\circ} \mathrm{C}$ for six weeks and pretreated with 24-epibrassinolide (Pociecha et al. 2016). The content of glucose and fructose decreased (by 33 and $29 \%$, respectively) and the content of sucrose and nystose increased only in the moderately winter resistant cv. Stach, but in the winter resistant cv. Dańkowskie Złote, a decrease in the glucose (44\%) and fructose $(36 \%)$ content was not accompanied by an increase of the sucrose and nystose content (Pociecha et al. 2016). Cold induced the accumulation of sugars also in seedlings of cold sensitive maize inbred line LM-17. Application of 24-epibrassinolide $(1 \mu \mathrm{M})$ further increased the glucose, sucrose, and starch content by about 15, 28 and $45 \%$, respectively, compared to cold stressed plants without BR treatment (Singh et al. 2012).

High temperature. Changes of sugar accumulation under high temperature are not as crucial as in the case of a cold acclimation. A marked decrease in total soluble sugar content was found in rice plants subjected to $40 / 30{ }^{\circ} \mathrm{C}(7 \mathrm{~d})$ compared to the control (Thussagunpanit et al. 2015b) but an increase in total soluble sugar content (by $23 \%$ ) was recorded in plants that were pretreated with 24-epi-brassinolide compared to plants that were subjected to heat without being sprayed with BR. In the same cultivar grown in the field during the hot season, 24-epibrassinolide increased the total soluble sugar content in the straw (by $107 \%$ ). The hormone also increased reducing sugar content in the straw (by $72 \%$ ) and the starch content in the straw (by $27 \%$ ), husk (by $24 \%$ ), and seeds (by $35 \%$ ) (Thussagunpanit et al. 2015a). Another rice cultivar exposed to a temperature of $35 / 32{ }^{\circ} \mathrm{C}$ for $12 \mathrm{~h}$ also demonstrated a decrease in the content of soluble sugars, which was further reduced by a mixture of plant growth regulators containing BRs (Fahad et al. 2016). Compared to rice, eggplant seedlings subjected to $43 / 38{ }^{\circ} \mathrm{C}$ ( $8 \mathrm{~d}$ ) have higher soluble sugar content compared to unstressed plants and the application of 24-epi-brassinolide $(0.1 \mu \mathrm{M})$ enhanced this effect $(\mathrm{Wu}$ et al. 2014).

Concluding remarks. In the case of heat treatment, the sugar accumulation in plants may fluctuate possibly due to a dependence on the general performance of photosynthesis. However, the increased sucrose concentration under cold lowers the freezing point of the cell solution, and thus it contributes to a higher resistance to frost. The stimulation of sucrose production along with an accumulation of protective sugars (like nystose) by BRs suggests that these hormones play a role in the process of acquiring frost resistance. A BR-stimulated increase in $\mathrm{CO}_{2}$ assimilation (described in previous chapter), may be the first step in this process, but BRs may also affect the activity of the enzymes that directly participate in sugar biosynthesis. The involvement of BR in the regulation of sucrose synthesis from glucose and fructose was studied for plants grown under optimal conditions, for example by $\mathrm{Yu}$ et al. (2004) and Janeczko et al. (2016). Yu et al. (2004) observed an increase in the activity of the enzymes that are involved in sucrose biosynthesis in cucumber after exogenous BR application. According to Janeczko et al. (2016), barley mutants with a reduced BR production accumulated more glucose and fructose and less sucrose than the wild type, which may also confirm dysfunctions in sucrose biosynthesis as a result of a BR deficiency. The mechanisms of the action BR on sugar biosynthesis require further confirmation in plants grown at low/high temperatures.

\section{Biosynthesis of proteins and accumulation of proline and glycinebetaine}

Low temperature. The acclimation of plants to low temperature requires an adjustment of a significant part of protein metabolism. In maize seedlings grown in a net house (max. temp. $17.6-24.5{ }^{\circ} \mathrm{C}$, min. temp. $2.8-4{ }^{\circ} \mathrm{C}$; $21 \mathrm{~d})$, the content of total proteins was $28 \%$ lower than in the control in a greenhouse $\left(25 / 18{ }^{\circ} \mathrm{C}\right)$ but 24-epibrassinolide $(1 \mu \mathrm{M})$ ameliorated this decrease (Singh et al. 2012).

Among the particular proteins with an accumulation stimulated by BRs under cold is the ATP-synthase $\beta$ subunit. Cold tolerant and sensitive cultivars of tomato sprayed with 24-epibrassinolide before cold $\left(12 / 6^{\circ} \mathrm{C}\right.$, $12 \mathrm{~d}$ ) accumulated more of the ATP-synthase $\beta$ subunit, thereby prevented a cold-induced decrease of its content (Cui et al. 2016).

In mango fruits stored at $5{ }^{\circ} \mathrm{C}(28 \mathrm{~d})$, brassinolide $(10 \mu \mathrm{M})$ increased the accumulation of the gene transcripts encoding the membrane-associated proteins: temperature induced lipocalin $(T I L)$, type II SK2 dehydrin (TSD), abscisic stress ripening-like protein $(A S R)$, and the remorin family proteins (REM) (Li et al. 2012). These proteins are associated with the stress response and may also perform important functions in membrane formation and repair. Cold-responsive (COR) proteins belong to hydrophilic polypeptides, which help to stabilise membranes, and thus may protect against damage induced by the cold (Tomashow 1998). According to Eremina et al. (2016), BRs enhance plant resistance against freezing stress via the regulation of the expression of COR genes. BR-controlled basic helixloop-helix transcription factor (CES), can contribute to the constitutive expression of the $C$-repeat/dehydrationresponsive element binding factors ( $C B F s$ ) transcriptional regulators that control the $C O R$ gene expression. $C B F 1$, $C B F 3$, and that $C O R 15 A$ transcript accumulation is increased in the wild type $A$. thaliana as a result of the application of 24-epibrassi-nolide (250 nM). BRIloe (BR-hypersignalling line) mutants have higher 
transcriptions of $C B F 1$ and $C B F 3$ as well as COR15A, COR15B, COR47, and COR78 compared to the wild type. In turn, the BR-signalling defective mutants bril301 and bril-1 had a significantly lower accumulation of these transcripts compared to the wild type plants. The effect of BRs on COR proteins was also confirmed by the studies of Kagale et al. (2007) and Divi et al. (2016), which proved that $C O R$ genes were up-regulated by BR. According to $\mathrm{Li}$ et al. (2017), BRs act via BZR1 (transcription factor - brassinazole resistant 1) in a CBFdependent manner in cold but also in a CBF-independent manner (Fig. 3). The dephosphorylation step of BZR1, which is blocked by BIN2 in the case of low BR content, is crucial (Wang et al. 2014). A higher content of BRs permits the inactivation of BIN2 and the dephosphorylation of BZR1, which in turn can directly activate BRresponsive genes or act indirectly in a CBF-dependent way (Wang et al. 2014, Li et al. 2017).

Proline is a specific amino acid that acts as an antioxidant, osmolyte, signalling molecule, and metal chelator (Hayat et al. 2012). In eggplants, exposed to $10 / 5{ }^{\circ} \mathrm{C}(8 \mathrm{~d})$, a drastic increase in the proline content (by $793 \%$ ) was observed compared to plants that were not subjected to cold (Wu et al. 2014a). Pretreatment with 24-epibrassinolide $(0.1 \mu \mathrm{M})$ additionally enhanced this effect by $87 \%$ (Wu et al. 2014a). Fruits of tomato that were treated with brassinolide $(6 \mu \mathrm{M})$ and stored at $1{ }^{\circ} \mathrm{C}$ (3 weeks) also had a $65 \%$ higher proline content compared to low-temperature-exposed fruits without BR application (Aghdam et al. 2012). Glycine betaine also acts as osmolyte (Ashraf and Foolad 2007). Seedlings of maize treated with 24-epibrassinolide $(1 \mu \mathrm{M})$ and exposed to cold show an increase of the glycine betaine content by about $85 \%$ compared to chilled plants that were not supplemented with this hormone (Singh et al. 2012).

High temperature. In plants at high temperature, protein content may decrease (melon, $42 / 32{ }^{\circ} \mathrm{C}, 2 \mathrm{~d}$ ) or increase (eggplant $43 / 38{ }^{\circ} \mathrm{C}, 8$ d) (Zhang et al. 2014, Wu et al. 2014b). The application of 24-epibrassinolide (0.05 $1.5 \mathrm{mg} \mathrm{dm}^{-3}$ ) increased protein content by an average of $35 \%$ in both species. A decrease in the protein content at $35 / 32{ }^{\circ} \mathrm{C}$ in rice was ameliorated by a mixture of plant growth regulators with BRs (Fahad et al. 2016). Brassinolide $(10 \mathrm{nM})$ increased also the protein content in cell cultures of Chlorella vulgaris grown at $30-40{ }^{\circ} \mathrm{C}$ (Bajguz 2009).

Under high temperature, heat shock proteins (HSP) play a chaperone function and prevent damage to many heat-sensitive cellular proteins. In seedlings of oilseed rape subjected to $45^{\circ} \mathrm{C}, h s p 101$, $h s p 90$, and $h s p 70$ genes were expressed, and 24-epibrassinolide promoted their transcripts accumulation, especially of $h s p 101$ and $h s p 90$ (Dhaubhadel et al. 1999, 2002). The 24-epibrassinolide also stimulated the accumulation of small HSPs (sHSPs) after heat treatment. A significant accumulation of HSP transcripts (particularly in plants that were treated with 24-epibrassinolide) was found during heat but after heat their accumulation decreased and in BR-treated plants even to a lower level than in control plants (Dhaubhadel et al. 2002). It is worth noting that Dockter et al. (2014) reported an increased amount of endogenous BRs in plants grown at high temperature. Finally, Samakovli et al. (2014) proposed HSP as important players in BRs signalling. Briefly, if a BR is not bound to a receptor, HSP90 in combination with BIN2 in the nucleus prevents the dephosphorylation of BES1 and BZR1 and the expression of BR-responsive genes. If $\mathrm{BR}$ is bound to receptor, the HSP-BIN2 complex is transferred to the cytoplasm and the dephosphorylation of BES1 and BZR1 permits the expression of BR-regulated genes.

Eggplant seedlings subjected to $43 / 38{ }^{\circ} \mathrm{C}$ for $8 \mathrm{~d}$ as well as melon seedlings subjected to $42 / 32{ }^{\circ} \mathrm{C}$ for $2 \mathrm{~d}$, were characterised by an increase in the proline content compared to the control (Wu et al. 2014b, Zhang et al. 2014). The application of 24-epibrassinolide $(0.1 \mu \mathrm{M})$ to the eggplant and 24-epibrassinolide $\left(0.05-1.5 \mathrm{mg} \mathrm{dm}^{-3}\right)$ to the melon enhanced this increase. Rice exposed to $35 / 32{ }^{\circ} \mathrm{C}$ and treated with a hormonal mixture containing BRs also had an increased proline content (Fahad et al. 2016).

Concluding remarks. Microarray and proteomic analyses of BR-treated plants and BR-deficient mutants proved that many genes are BR-regulated (Yang and Komatsu 2004, Deng et al. 2007). A large part of this knowledge has been obtained from studies of plants grown under optimum temperature. More detailed studies should now be devoted to the aspect of low/high temperature treatments, which would be helpful in explaining the mechanisms of BR action under these stresses. Currently, it appears that BRs are engaged in controlling the COR expression at low temperature and $H S P$ expression at high temperature. They also promote the accumulation of the ATP-synthase $\beta$ subunit and the transcripts of the TIL, TSD, ASR, and REM, which are important in the function, formation, and repair of membranes.

Many studies have indicated a positive relationship between plant stress tolerance and the accumulation of proline and glycine betaine (Ashraf and Foolad 2007). The BR-stimulated accumulation of both osmolytes may then support plant acclimation to low or high temperature. The study of Janeczko et al. (2016) on barley BR-deficient mutants demonstrated that these plants - under optimum growth conditions and under drought - indeed accumulated less proline than the wild type, which suggests the importance of BR in regulating the proline content. According to Farriduddin et al. (2009), BRs activate the proline biosynthesis enzymes.

A search for other proteins that may directly or indirectly contribute to a brassinosteroid-mediated increase in the tolerance to low/high temperature is an open question. 


\section{Other effects of BRs application}

Low temperature: The acclimation of plants to a low temperature is connected with the significant changes in hormonal homeostasis, especially in the content of the socalled stress hormones. C. bungeana cell cultures that were subjected to 0 and $4{ }^{\circ} \mathrm{C}(3 \mathrm{~d})$ accumulated abscisic acid [ABA);17 and 22 ng g g $^{-1}$ (f.m.)], respectively. Cells cultured with 24 -epibrassinolide $(0.1 \mu \mathrm{M})$ accumulated 33 and $27 \mathrm{ng}(\mathrm{ABA}) \mathrm{g}^{-1}$ (f.m.) at 0 and $4{ }^{\circ} \mathrm{C}$, respectively (Liu et al. 2011).

Application of 24-epibrassinolide $\left(0.25 \mathrm{mg} \mathrm{dm}^{-3}\right)$ to perennial ryegrass combined with cold $\left(4^{\circ} \mathrm{C}, 6\right.$ weeks $)$ resulted in an increased content of the ethylene precursor (ACC) compared to the plants without BR treatment (Pociecha et al. 2017). The jasmonic acid content increased only in cv. Flinston and no effect of 24-epibrassinolide on salicylic acid content was noted.

In addition to the well-known effect of BRs on Rubisco or antioxidant enzymes activity, the activity of other important enzymes has also been shown. In cucumber plants under cold $\left(5 / 3{ }^{\circ} \mathrm{C}, 18 \mathrm{~h}\right)$, nitrate reductase activity was reduced by $27 \%$ compared to unstressed plants; however, 28-homobrassinolide $\left(10^{-8} \mathrm{M}\right)$ neutralised this effect (Farriduddin et al. 2011). Pectin methylestereases (PMEs) play a significant role in plant cold/frost tolerance as they catalyze the dimethylesterification of cell wall polygalacturonans (Micheli 2001, Qu et al. 2011). The activity of PMEs was markedly increased in the wild type $A$. thaliana grown at $0{ }^{\circ} \mathrm{C}(24 \mathrm{~h})$ and less increase was observed in the bril116 homozygous mutant, whereas in the bzrl-D mutant, the PME activity was similar as in the wild type $(\mathrm{Qu}$ et al. 2011). Ammonia-lyase (PAL) is a key enzyme in the metabolism of phenols, which help to protect plants against stress (Lafuente et al. 2003). Tomato fruits that were stored at $1{ }^{\circ} \mathrm{C}$ ( 3 weeks) had increased PAL activity; brassinolide further enhanced the effect and simultaneously increased the total phenol content (Aghdam et al. 2012). An increase in soluble phenolics was also noted in
LOW TEMPERATURE

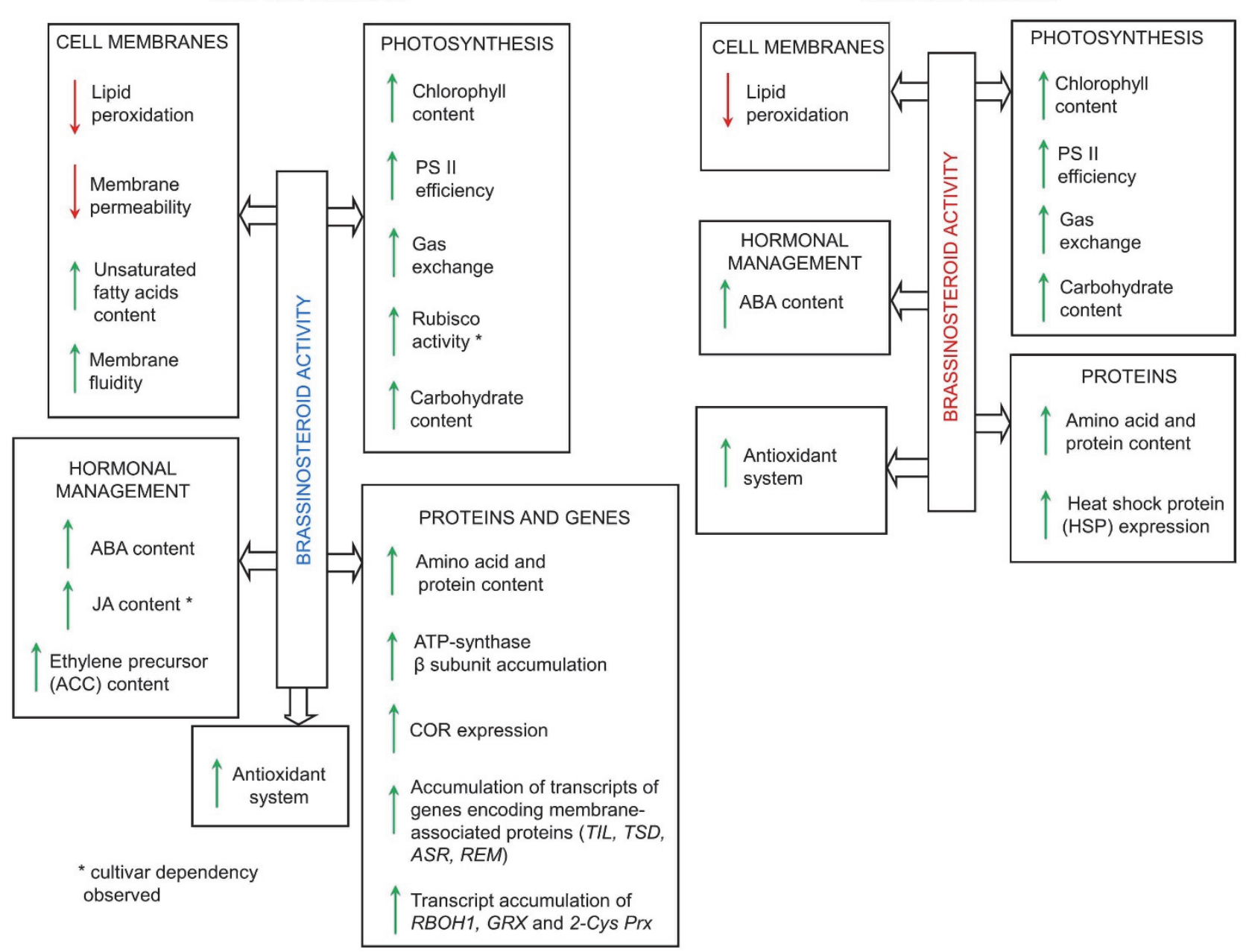

HIGH TEMPERATURE

Fig. 4. Multidirectional activity of BRs in the regulation of metabolism of plants exposed to low and high temperatures. 
the perennial ryegrass cv. Flinston (but not in cv. Amarant) grown at $4{ }^{\circ} \mathrm{C}$ for 6 weeks and treated with 24-epibrassinolide $\left(0.25 \mathrm{mg} \mathrm{dm}^{-3}\right)$ (Pociecha et al. 2017). To the best of our knowledge, there is no data about the effect of BRs on the activation of the above-mentioned enzymes in high temperature.

High temperature: Plant hormonal balance is also changed by a high temperature. Chlorella vulgaris cells at temperatures of 30,35 , and $40{ }^{\circ} \mathrm{C}(3 \mathrm{~h})$ accumulated higher amounts of ABA, which increased along with the increase in temperature to $1.65,2.2$, and $2.6 \mathrm{ng} \mathrm{g}^{-1}$ (f.m.), respectively). Addition of $10 \mathrm{nM}$ brassinolide stimulated ABA accumulation at $40{ }^{\circ} \mathrm{C}$ to $4.32 \mathrm{ng}(\mathrm{ABA}) \mathrm{g}^{-1}$ (f.m.) (Bajguz 2009).

Concluding remarks: Plant hormones remain in the connection network and control their own biosynthesis and transport (Weiss and Ori 2007). BRs also contribute to the functioning of this network (Zhang et al. 2009), but little is specifically known about their role in terms of temperature stress. As is shown here, BRs increase the accumulation of $\mathrm{ABA}$ at low or high temperature. Barley mutants in the $H v D W A R F$ gene encoding C6-oxidase, which is involved in BR biosynthesis, accumulated a significantly lower amount of ABA compared to the wild type plants (Janeczko et al. 2016), which may confirm an interplay between these hormones. During cold hardening of ryegrass, BR also stimulated the accumulation of other stress hormones, jasmonic acid and ethylene precursor ACC. The role of BRs in the hormonal network of plants that are exposed to high temperature and especially to low temperature (significant in hardening to frost) definitely requires further studies.

The detailed mechanisms that are responsible for BR impact on the activity of the aforementioned enzymes remain unknown. We can only theoretically state that BRs act by up-regulating the genes coding those enzymes. It is also possible that there is an indirect effect of BRs via the stimulation of the production of chaperones (HSP) that, among others, may help to protect the cell enzymatic system against a loss of activity under temperature stress.

\section{Improvement of plant resistance to low and high temperatures}

Low temperature: The viability of cells of Chorispora bungeana, measured by 2,3,5-triphenyltetrazolium chloride (TTC) reduction test, decreased during growth at 0 and $4{ }^{\circ} \mathrm{C}$ for $3-5 \mathrm{~d}$, but supplementation with 24-epibrassinolide $\left(0.05\right.$ and $\left.0.1 \mathrm{mg} \mathrm{dm}^{-3}\right)$ counteracted this effect (Liu et al. 2009, 2011). Brassinosteroids also reduce the cold damage to plants such as cucumber or maize, which are characterized by a relatively low cold tolerance. About $30 \%$ reduction in the shoot and root length, leaf area, and fresh and dry masses of cucumber exposed to $5 / 3{ }^{\circ} \mathrm{C}$ for $18 \mathrm{~h}$ were largely prevented by $10^{-8}$ M 28-homobrassinolide (Farriduddin et al. 2011). In the cucumber cv. Jinchun No. 4, 24-epibrassinolide $(0.1 \mu \mathrm{M})$ when applied on the $5^{\text {th }}$ day of cold $\left(10 / 7{ }^{\circ} \mathrm{C}\right)$ counteracted the reductions in the growth and dry mass but the effect was more pronounced in plants treated under high irradiance (Jiang et al. 2013). Singh et al. (2012) found that seedlings of maize exposed to cold in net house, showed a reduction in plant height (35\%) and fresh mass $(24 \%)$ compared to the those in a greenhouse. The pre-treatment with $1 \mu \mathrm{M}$ 24-epibrassinolide increased plant height and fresh and dry masses by about 15,36 , and $2 \%$, respectively, compared to the plants without BR pre-treatment. Similar effects were also observed by He et al. (1991) for brassinolide pre-treated maize.

The application of BRs provides a chance to minimise fruit damage during cold storage. A marked reduction of chilling injury index (CI) was observed after immersion of tomato cv. Newton fruits in 3 and $6 \mu \mathrm{M}$ brassinolide solution compared to fruits that were not BR-treated and stored at $1{ }^{\circ} \mathrm{C}$ for 3 weeks (Aghdam et al. 2012). The similar effect of brassinolide $(10 \mu \mathrm{M})$ on CI was observed for mango fruits stored at $5{ }^{\circ} \mathrm{C}$ for $28 \mathrm{~d}$ ( $\mathrm{Li}$ et al. 2012). The BR application limited the sunken lesions of the pericarp and pulp darkening accompanying tissue necrosis. Pepper fruits also responded to storage at $3{ }^{\circ} \mathrm{C}$ for $18 \mathrm{~d}$ by the occurrence of damage such as surface pitting and calyx discoloration (Wang et al. 2012). A gradual increase in the CI index was observed with the duration of fruit storage and the greatest damage was recorded on the last $\left(18^{\text {th }}\right)$ day. Pre-treatment of the fruits with a $15 \mu \mathrm{M}$ brassinolide solution alleviated these effects by reducing the $\mathrm{CI}$ index by about $69 \%$ compared to the fruits that were stored in the cold without brassinolide treatment.

Relatively new research was dedicated to the possibility of limiting frost damage by BR. Winter rye plants sprayed with 24-epibrassinolide $\left(0.25 \mathrm{mg} \mathrm{dm}^{-3}\right)$ before a 6-week acclimation at $4{ }^{\circ} \mathrm{C}$ showed less frost damage and a higher survival rate (Pociecha et al. 2016). Winter wheat seedlings sprayed with 24-epibrassinolide $\left(0.25\right.$ or $\left.0.05 \mathrm{mg} \mathrm{dm}^{-3}\right)$, cold-acclimated and then exposed to $-12^{\circ} \mathrm{C}$ had a higher survival rate than those that were not BR-treated (Janeczko 2016). Perennial ryegrass acclimated at $4{ }^{\circ} \mathrm{C}$ for 6 weeks and treated with 24-epibrassinolide $\left(0.25 \mathrm{mg} \mathrm{dm}^{-3}\right)$ had an increased frost tolerance (by $35 \%$ ) compared to plants without the BR treatment (Pociecha et al. 2017). The importance of BRs in the process of acclimation and frost tolerance was confirmed by a study on A. thaliana mutants with impaired BR-signalling (Eremina et al. 2016). Compared 
to the wild type, BR-hypersignalling mutants $35 S$ :BRI1GFP (BRI loe) that were exposed to $-10{ }^{\circ} \mathrm{C}(6 \mathrm{~h})$ demonstrated a higher frost tolerance. In turn, bri1-301 and bril-1 mutants with disturbances in BR-signalling exhibited a drastically reduced frost tolerance. The rate of survival of the wild type plants was about $50 \%$, while for BRI $10 e$, it was 70\%, and for bri1-301 only a few percent. Plants of the bril-1 mutant did not survive the frost.

High temperature: Bromegrass cell suspension cultures treated with $10 \mu \mathrm{M}$ 24-epibrassinolide had significantly higher cell viability at high temperatures $\left(40-45^{\circ} \mathrm{C}\right.$, 45 - $90 \mathrm{~min}$ ) than the untreated cultures (Wilen et al. 1995). In one of the first studies that showed the alleviating effects of BRs on whole plants at high temperature, Dhaubhadel et al. (1999) assessed the effect of $45{ }^{\circ} \mathrm{C}(4 \mathrm{~h})$ on oilseed rape and tomato. This temperature was lethal for most of the plants, but 24-epibrassinolide $(1 \mu \mathrm{M})$ increased plant survival. In the studies of Mazorra et al. (2011), all of the tomato cv. Ailsa Craig seedlings and approximately $80 \%$ of cv. Money-maker seedlings survived at $45^{\circ} \mathrm{C}$ for $4 \mathrm{~h}$ but not for 8 h. 24-Epibrassinolide $(1 \mu \mathrm{M})$ improved the survival of plants stressed for 5, 6, and $7 \mathrm{~h}$. A temperature of $45^{\circ} \mathrm{C}(7 \mathrm{~h})$ was then tested on tomato the brassinosteroid mutants: curl3-abs, $d^{x}$, and 35SD. Approximately $90 \%$ of the $c u r l 3^{-a b s}$ seedlings survived but only $18-30 \%$ of $d^{x}$ and 35SD seedlings survived. The survival rate of the $d^{x}$ mutants that were treated with 24-epibrassinolide $(1 \mu \mathrm{M})$ was approximately 2.6-fold higher compared to the $d^{x}$ plants that were not treated. 24-Epibrassinolide also improved the survival of the curl $^{-a b s}$ seedlings. In eggplant (cv. Huqie 9), a temperature of $43 / 38{ }^{\circ} \mathrm{C}(8 \mathrm{~d})$ reduced plant height, stem diameter, and shoot and root fresh masses by $28,35,61$, and $58 \%$, respectively, compared to the control (Wu et al. 2014b). 24-Epibrassi-nolide $(0.1 \mu \mathrm{M})$ increased the values by $26,43,55$ and $43 \%$, respectively, compared to the control (high temperature, no BR spraying). A high temperature $\left(42 / 32{ }^{\circ} \mathrm{C}, 2 \mathrm{~d}\right)$ decreased fresh masses of shoots and roots in melon plants (Zhang et al. 2013). 24-Epibrassinolide $\left(1 \mathrm{mg} \mathrm{\textrm {dm } ^ { - 3 }}\right)$ treated plants had a higher mass by about $14-27 \%$. 24-Epibrassinolide also decreased the heat injury index as measured by observations of leaf yellowing, curling, and senescence compared to the stressed plants that did not undergo hormone spraying. In another work of these authors on the same species, a higher BR concentration $\left(1.5 \mathrm{mg} \mathrm{dm}^{-3}\right)$ was also effective (Zhang et al. 2014). In rice, a temperature of $40 / 30{ }^{\circ} \mathrm{C}(7 \mathrm{~d})$ reduced the shoot and root fresh masses and leaf area, but this effect was limited by 24-epibrassinolide $\left(10^{-8} \mathrm{M}\right)$ (Thussagunpanit et al. $2015 \mathrm{~b}$ ). In the same cultivar grown in the field during the hot season (February to May 2012, Thailand), 24-epibrassinolide increased the number of filled seeds per panicle by $16 \%$ and increased the seed mass by $35 \%$ (Thussangunpanit et al. 2015a).

A high temperature during plant development may negatively affect pollen viability. Tomato pollen that were inoculated on a medium with $1 \mu \mathrm{M}$ 24-epibrassinolide and exposed to $35^{\circ} \mathrm{C}$ for $4 \mathrm{~h}$ showed a higher germination, enhanced tube growth, and lower pollen bursting compared to the pollen without BR treatment (Singh and Shono 2003). In rice at a temperature of $35 / 32{ }^{\circ} \mathrm{C}$, a reduction in pollen fertility, anther dehiscence, number of germinated pollens on the stigma and total number of pollen occurred (Fahad et al. 2016). Plants administered with a mixture of growth regulators containing BRs had higher values of the aforementioned parameters in comparison to the stressed plants that had not been sprayed.

Concluding remarks: To conclude, plant resistance to high/low temperatures is an important issue in agriculture and horticulture as well as in fruit and vegetable storage. Many methods are used to improve plant resistance, including applications of protective compounds (Senaratna et al. 1988). The results summarised in this chapter show that BRs have the potential to reduce many of the negative effects of low/high temperatures, which encourages the future practical application of BRs.

\section{Conclusions and future perspectives}

The negative effects of low or high temperature are reduced in plants to which BRs are applied before or during stress. The following ways of BR action are possible: alterations in the membrane physicochemical properties, regulation of the expression of some genes (HSP, COR), and regulation of metabolism through other hormones or signalling molecules (ABA or hydrogen peroxide) (Figs. 4 and 5). Most of the literature on this subject is related to the effect of exogenous BRs on plants that are subjected to low/high temperatures. In the future, more emphasis should be placed on studying the impact of low/high temperatures on BR-biosynthesis/signalling

mutants or on plants that are treated with BR inhibitors. This would strengthen the knowledge about the role of these hormones in plant responses to low/high temperatures. Nevertheless, results from studies with the exogenous application of BRs on plants that are exposed to low/high temperatures are a good starting point for agricultural/horticultural practice. Agrochemicals with BRs may help to protect crops against the negative impact of low/high temperatures (i.e., by improving frost resistance). It is worth noting that BRs act in very small concentrations and are natural biodegradable substances. Simultaneously, the use of classical breeding methods or 
genetic engineering methods to modulate the BR content in plants or to change the signal transduction pathways that are derived from the BR receptors are promising for the creation of new more stress resistant plants.

This article is distributed under the terms of the Creative Commons Attribution License which permits any use, distribution, and reproduction in any medium, provided the original author(s) and the source are credited.

\section{References}

Aghdam, M.S., Asghari, M., Farmani, B., Mohayeji, M., Moradbeygi, H.: Impact of postharvest brassinosteroids treatment on PAL activity in tomato fruit in response to chilling stress. - Sci. Hort. 144: 116-120, 2012.

Ashraf, M., Foolad, M.R.: Roles of glycine betaine and proline in improving plant abiotic stress resistance. - Environ. exp. Bot. 59: 206-216, 2007.

Bajguz, A.: Brassinosteroid enhanced the level of abscisic acid in Chlorella vulgaris subjected to short-term heat stress. - J. Plant Physiol. 166: 882-886, 2009.

Bajguz, A., Tretyn, A.: The chemical characteristic and distribution of brassinosteroids in plants. - Phytochemistry 62: 1027-1046, 2003.

Clouse, S.D.: A history of brassinosteroid research from 1970 through 2005: thirty-five years of phytochemistry, physiology, genes and mutants. - J. Plant Growth Regul. 34: 828-844, 2015.

Cui, L., Zou, Z., Zhang, J., Zhao, Y., Yan, F.: 24Epibrassinoslide enhances plant tolerance to stress from low temperatures and poor light intensities in tomato (Lycopersicon esculentum Mill.). - Funct. integr. Genomics 16: 29-35, 2016.

Deng, Z., Zhang, X., Tang, W., Oses-Prieto J.A., Suzuki, N., Gendron, J. M., Chen, H., Guan, S., Chalkley, R.J., Peterman, T.K., Burlingame, A.L., Wang, Z.-Y.: A proteomic study of brassinosteroid response in Arabidopsis. - Mol. Cell Proteomics 6: 2058-2071, 2007.

Dhaubhadel, S., Browning, K.S., Gallie, D.R., Krishna, P.: Brassinosteroid functions to protect the translational machinery and heat-shock protein synthesis following thermal stress. - Plant J. 29: 681-691, 2002.

Dhaubhadel, S., Chaudhary, S., Dobinson, K. F., Krishna, P.: Treatment with 24-epibrassinolide, a brassinosteroid, increases the basic thermotolerance of Brassica napus and tomato seedlings. - Plant mol. Biol. 40: 333-342, 1999.

Divi, U.K., Rahman, T., Krishna, P.: Gene expression and functional analyses in brassinosteroid-mediated stress tolerance. - Plant Biotechnol. J. 14: 419-432, 2016.

Dockter, C., Gruszka, D., Braumann, I., Druka, A., Druka, I., Franckowiak, J., Gough, S.P., Janeczko, A., Kurowska, M., Lundqvist, J., Lundqvist, U., Marzec, M., Matyszczak, I., Müller, A. H., Oklešt'ková, J., Schulz, B., Zakhrabekova, S., Hansson, M.: Induced variations in brassinosteroid genes define barley height and sturdiness, and expand the "Green Revolution" genetic toolkit. - Plant Physiol. 166: 1912$1927,2014$.

Eremina, M., Unterholzner, S.J., Rathnayake, A.I., Castellanos, M., Khan, M., Kugler, K.G., May, S.T., Mayer, K.F.X., Rozhon, W., Poppenberger, B.: Brassinosteroids participate in the control of basal and acquired freezing tolerance of plants. - Proc. nat. Acad. Sci. USA 113: 5982-5991, 2016.
Fahad, S., Hussain, S., Saud, S., Khan, F., Hassan, S., Amanullah, N.W., Arif, M., Wang, F., Huang, J.: Exogenously applied plant growth regulators affect heatstressed rice pollens. - J. Agron Crop Sci. 202: 139-150, 2016.

Fariduddin, Q., Yusuf, M., Chalkoo, S., Hayat, S., Ahmad A.: 28-homobrassinolide improves growth and photosynthesis in Cucumis sativus L. through an enhanced antioxidant system in the presence of chilling stress. - Photosynthetica 49: 55-64, 2011.

Filek, M., Rudolphi-Skórska, E., Sieprawska, A., Kvasnica, M., Janeczko, A.: Regulation of the membrane structure by brassinosteroids and progesterone in winter wheat seedlings exposed to low temperature. - Steroids 128: 37-45, 2017.

Fujioka, S., Yokota, T.: Biosynthesis and metabolism of brassinosteroids. - Physiol. Plant. 100: 710-715, 1997.

Grove, M.D., Spencer, G.F., Rohwedder, W.K., Mandava, N., Worley, J.F., Warthen, J.D., Jr., Steffens, G.L., FlippenAnderson, J.L., Cook, J.C., Jr.: Brassinolide, a plant growthpromoting steroid isolated from Brassica napus pollen. Nature 281: 216-217, 1979.

Hayat, S., Hayat, Q., Alyemeni, M.N., Wani, A.S., Pichtel, J., Ahmad, A.: Role of proline under changing environments: a review. - Plant Signal Behav. 7: 1456-1466, 2012.

He, R.-Y., Wang, G.-J., Wang, X.-S.: Effects of brassinolide on growth and chilling resistance of maize seedlings. - In: Cutler, G.H., Yokota, T, Adam, G. (ed.): Brassinosteroids. Vol. 19. Pp. 220-230. American Chemical Society, Washington 1991.

Henry, R.P.: Multiple roles of carbonic anhydrase in cellular transport and metabolism. - Annu. Rev. Plant Physiol. 58: 523-538, 1996.

Hodges, D. M., DeLong, J.M., Forney, C.F., Prange, R.K.: Improving the thiobarbituric acid-reactive-substances assay for estimating lipid peroxidation in plant tissues containing anthocyanin and other interfering compounds. - Planta 207: 604-611, 1999.

Hörtensteiner, S., Kräutler, B.: Chlorophyll breakdown in higher plants. - BBA Bioenergetics 1807: 977-988, 2011.

Horváth, I., Glatz, A., Nakamoto, H., Mishkind, M.L., Munnik, T., Saidi, Y., Goloubinoff, P., Harwood, J.L., Vigh, L.: Heat shock response in photosynthetic organisms: membrane and lipid connections. - Progr. Lipid Res. 51: 208-220, 2012.

Hu, W.H., Wu, Y., Zeng, J.Z., He, L., Zeng, Q.M.: Chillinduced inhibition of photosynthesis was alleviated by 24epibrassinolide pretreatment in cucumber during chilling and subsequent recovery. - Photosynthetica 48: 537-544, 2010.

Janeczko, A. (ed): Występowanie, transport i wybrane aspekty aktywności fizjologicznej brasinosteroidów w roślinach uprawnych $\mathrm{z}$ rodzin Poaceae I Fabaceae. [Presence, 
Transport and PhysiologicalAactivity of Brassinosteroids in Crop Plants from Poaceae and Fabaceae family]. - Polish Academy of Sciences, Krakow 2016. [In Polish.]

Janeczko, A., Gruszka, D., Pociecha, E., Dziurka, M., Filek, M., Jurczyk, B., Kalaji, H.M., Kocurek, M., Waligórski, P.: Physiological and biochemical characterisation of watered and drought-stressed barley mutants in the HvDWARF gene encoding C6-oxidase involved in brassinosteroid biosynthesis. - Plant Physiol. Biochem. 99: 126-141, 2016.

Janeczko, A., Gullner, G., Skoczowski, A., Dubert, F., Barna, B.: Effects of brassinosteroid infiltration prior to cold treatment on ion leakage and pigment contents in rape leaves. - Biol. Plant. 51: 355-358, 2007.

Janeczko, A., Hura, K., Skoczowski, A., Idzik, I., BiesagaKościelniak, J., Niemczyk, E.: Temperature-dependent impact of 24-epibrassinolide on the fatty acid composition and sugar content in winter oilseed rape callus. - Acta Physiol Plant. 31: 71-79, 2009.

Janeczko, A., Oklešt'ková, J., Pociecha, E., Kościelniak, J., Mirek, M.: Physiological effects and transport of 24epibrassinolide in heat-stressed barley. - Acta Physiol. Plant. 33: 1249-1259, 2011.

Jiang, Y.-P., Huang, L.-F., Cheng, F., Zhou, Y.-H., Xia, X.-J., Mao, W.-H., Shi, K., Yu, J.-Q.: Brassinosteroids accelerate recovery of photosynthetic apparatus from cold stress by balancing the electron partitioning, carboxylation and redox homeostasis in cucumber. - Physiol Plant. 148: 133-145, 2013.

Jin, S.H., Li, X.Q., Wang, G.G., Zhu, X.T.: Brassinosteroids alleviate high-temperature injury in Ficus concinna seedlings via maintaining higher antioxidant defence and glyoxalase systems. - AoB Plants 7: plv009, 2015.

Johnson, G., Williams, J.P.: Effect of growth temperature on the biosynthesis of chloroplastic galactosyldiacylglycerol molecular species in Brassica napus leaves. - Plant Physiol. 91: 924-929, 1989.

Kagale, S., Divi, U.K., Krochko, J.E., Keller, W.A., Krishna, P.: Brassinosteroid confers tolerance in Arabidopsis thaliana and Brassica napus to a range of abiotic stresses. - Planta 225: 353-364, 2007.

Kim, T.-W., Chang, S.C.,. Lee, J.S, Takatsuto, S., Yokota, T., Kim, S.-K.: Novel biosynthetic pathway of castasterone from cholesterol in tomato. - Plant Physiol. 135: 1231-1242, 2004.

Kim, Y.-S., Joo, S.-H., Hwang, J.-Y., Park, C.H., Kim, S.-K.: Characterization of C29-brassinosteroids and their biosynthetic precursors in immature seeds of Phaseolus vulgaris. - Bull. korean chem. Soc. 27: 1117-1118, 2006

Kreslavski, V.D., Los, D.A., Allakhverdiev, S.I., Kuznetsov, V.V.: Signaling role of reactive oxygen species in plants under stress. - Russ. J Plant Physiol. 59: 141-154, 2012.

Krishna, P.: Brassinosteroid-mediated stress responses. - J. Plant Growth Regul. 22: 289-297, 2003.

Lafuente, M.T., Zacarias, L., Martınez-Téllez, M.A., SanchezBallesta, M.T., Granell, A.: Phenylalanine ammonia-lyase and ethylene in relation to chilling injury as affected by fruit age in citrus. - Postharvest Biol. Technol. 29: 308-317, 2003.

Li, B., Zhang, C., Cao, B., Qin, G., Wang, W., Tian, S.: Brassinolide enhances cold stress tolerance of fruit by regulating plasma membrane proteins and lipids. - Amino Acids 43: 2469-2480, 2012.

Li, J.M., Jin, H.: The regulation of brassinosteroids signaling. -
Trends Plant Sci. 12: 37-41, 2007.

Li, H., Ye, K., Shi, Y., Cheng, J., Zhang, X., Yang, S.: BZR1 positively regulates freezing tolerance via CBF-dependent and CBF-independent pathways in Arabidopsis. - Mol. Plants 10: 545-559, 2017.

Liu, Y., Jiang, H., Zhao, Z., An, L.: Abscisic acid is involved in brassinosteroids-induced chilling tolerance in the suspension cultured cells from Chorispora bungeana. - J. Plant Physiol. 168: 853-862, 2011.

Liu, Y., Zhao, Z., Si, J., Di, C., Han, J., An, L.: Brassinosteroids alleviate chilling-induced oxidative damage by enhancing antioxidant defense system in suspension cultured cells of Chorispora bungeana. - Plant Growth Regul. 25: 207-214, 2009.

Mazorra, L.M., Holton, N., Bishop, G.J., Núñez, M.: Heat shock response in tomato brassinosteroid mutants indicates that thermotolerance is independent of brassinosteroid homeostasis. - Plant Physiol. Biochem. 49: 1420-1428, 2011.

Micheli, F.: Pectin methylesterases: cell wall enzymes with important roles in plant physiology. - Trends Plant Sci. 6: 414-419, 2001.

Mitchell, J.W., Mandava, N., Worley, J.F., Plimmer, J.R., Smith, M.V.: Brassins - a new family of plant hormones from rape pollen. - Nature 225: 1065-1066, 1970.

Morillon, R., Catterou, M., Sangwan, R.S., Sangwan, B.S., Lassalles, J.P.: Brassinolide may control aquaporin activities in Arabidopsis thaliana. - Planta 212: 199-204, 2001.

Parthier, B.: The role of phytohormones (cytokinins). III Chloroplast development. - Biochem. Physiol. Pflanz. 174: 173-214, 1979.

Park, S.C., Kim, T.-W., Kim, S.-K.: Identification of brassinosteroids with 24R-methyl in immature seeds of Phaseolus vulgaris. - Bull. korean chem. Soc. 21: 12741276, 2000.

Pociecha, E., Dziurka, M., Oklestkova, J., Janeczko, A.: Brassinosteroids increase winter survival of winter rye (Secale cereale L.) by affecting photosynthetic capacity and carbohydrate metabolism during the cold acclimation process. - Plant Growth Regul. 80: 127-135, 2016.

Pociecha, E., Dziurka, M., Waligórski, P., Krępski, T., Janeczko, A.: 24-Epibrassinolide pre-treatment modifies cold-induced photosynthetic acclimation mechanisms and phytohormone response of perennial ryegrass in cultivardependent manner. - J. Plant Growth. Regul. 36: 618-628, 2017.

Qu, T., Liu, R., Wang, W., An, L., Chen, T., Liu, G., Zhao, Z.: Brassinosteroids regulate pectin methylesterase activity and AtPME41 expression in Arabidopsis under chilling stress. Cryobiology 63: 111-117, 2011

Samakovli, D., Margaritopoulou, T., Prassinos, C., Milioni, D., Hatzopoulos, P.: Brassinosteroid nuclear signaling recruits HSP90 activity. - New Phytol. 203: 743-757, 2014.

Sakuraba, Y., Lee, S.H., Kim, Y.S., Park, O.K., Hörtensteiner, S., Paek, N.C.: Delayed degradation of chlorophylls and photosynthetic proteins in Arabidopsis autophagy mutants during stress-induced leaf yellowing. - J. exp. Bot. 65: 3915-3925, 2014.

Schaller, H.: The role of sterols in plant growth and development. - Progr. Lipid Res. 42: 163-175, 2003.

Senaratna, T., Mackay, C.E., McKersie, B.D., Fletcher, R.A.: Uniconazole-induced chilling tolerance in tomato and its 
relationship to antioxidant content. - J. Plant Physiol. 133: 56-61, 1988.

Shu, H.M., Guo, S.Q., Gong, Y.Y., Jiang, J.W., Ni, W.C.: RNA-seq analysis reveals a key role of brassinolideregulated pathways in $\mathrm{NaCl}$-stressed cotton. - Biol. Plant. 61: 667-674, 2017.

Singh I., Kumar U., Singh S.K., Gupta C., Singh M., Kushwaha S.R.: Physiological and biochemical effect of 24epibrassinoslide on cold tolerance in maize seedlings. Physiol. mol. Biol. Plants 18: 229-236, 2012.

Singh, I., Shono, M.: Effect of 24-epibrassinolide on pollen viability during heat-stress in tomato. - Indian J. exp. Biol. 41: 174-176, 2003.

Song, Y.L., Dong, Y.J., Tian, X.Y., Kong, J., Bai, X.Y., Xu, L.L., He, Z.L.: Role of foliar application of 24epibrassinolide in response of peanut seedlings to iron deficiency. - Biol. Plant. 60: 329-342, 2016.

Takatsuto, S., Kosuga, N., Abe, B-I., Noguchi, T., Fujioka, S., Yokota, T.: Occurrence of potential brassinosteroid precursor steroids in seeds of wheat and foxtail millet. - J. Plant Res. 112: 27-33, 1999.

Thussagunpanit, J., Jutamanee, K., Kaveeta, L., Chai-arree, W., Pankean, P., Homvisasevongsa, S., Suksamrarn, A.: Comparative effects of brassinosteroid and brassinosteroid mimic on improving photosynthesis, lipid peroxidation and rice seed set under heat stress. - J. Plant Growth Regul. 34: 320-331, 2015 b.

Thussagunpanit, J., Jutamanee, K., Sonjaroon, W., Kaveeta, L., Chai-arree, W., Pankean, P., Suksamrarn, A.: Effects of brassinosteroid and brassinosteroid mimic on photosynthetic efficiency and rice yield under heat stress. - Photosynthetica 53: 312-320, 2015a.

Tomashow, M.F.: Role of cold-responsive genes in plant freezing tolerance. - Plant Physiol. 118: 1-7, 1998.

Wang, Q., Ding, T., Gao, L., Pang, J., Yang, N.: Effect of brassinolide on chilling injury of green bell pepper in storage. - Sci. Hort. 144: 195-200, 2012.

Wang, W., Bai, M.Y., Wang, Z.Y.: The brassinosteroid signalling network - a paradigm of signal transduction. Curr. Opin. Plant Biol. 21: 147-153, 2014.

Wang, Z.Y., Wang, Q.M., Chong, K., Wang, L., Bai. M.Y., Jia, C.G.: The brassinosteroid signal transduction pathway. Cell Res. 16: 427-434, 2006.

Weiss, D., Ori, N.: Mechanisms of cross talk between gibberellin and other hormones. - Plant Physiol. 144: 12401246, 2007.

Wilen, R., Sacco, W., Gusta, M. L. V., Krishna, P.: Effects of 24-epibrassinolide on freezing and thermotolerance of bromegrass (Bromus inermis) cell cultures. - Physiol. Plant. 95: 195-202, 1995.

Winter, J., Schneider, B., Meyenburg, S., Strack, D., Adam, G.: Monitoring brassinosteroid biosynthetic enzymes by fluorescent tagging and HPLC analysis of their substrates and products. - Phytochemistry 51: 237-242, 1999.

Wu, X., Yao, X., Chen, J., Zhu, Z., Zhang, H., Zha, D.: Brassinosteroids protect photosynthesis and antioxidant system of eggplant seedlings from high-temperature stress. Acta Physiol Plant. 36: 251-261, 2014b.

Wu, X.X., He, J., Zhu, Z.W., Yang, S.J., Zha, D.S.: Protection of photosynthesis and antioxidative system by 24-epibrassinolide in Solanum melongena under cold stress. - Biol. Plant. 58: 185-188, 2014a.
Xia, X.-J., Huang, L.F., Zhou, Y.H., Mao, W.H., Shi, K., Wu, J.X., Asami, T., Chen, Z., Yu, J.Q.: Brassinosteroids promote photosynthesis and growth by enhancing activation of Rubisco and expression of photosynthetic genes in Cucumis sativus. - Planta 230: 1185-1196, 2009b.

Xia, X.-J., Wang, Y.-J., Zhou, Y.-H., Tao, Y., Mao, W.-H., Shi, K., Asami, T., Chen, Z., Yu, J.-Q.: Reactive oxygen species are involved in brassinosteroid-induced stress tolerance in cucumber. - Plant Physiol. 150: 801-814, 2009a.

Xia, X.-J., Zhou, Y.-H., Shi, K., Zhou, J., Foyer, C.H., Yu, J.Q.: Interplay between reactive oxygen species and hormones in the control of plant development and stress tolerance. - J. exp. Bot. 66: 2839-2856, 2015.

Xia, X.-J., Fang, P.-P., Guo, X., Qian, X.-J., Zhou, J., Shi, K., Zhou, Y.-H., Yu, J.-Q.: Brassinosteroid-mediated apoplastic $\mathrm{H}_{2} \mathrm{O}_{2}$-glutaredoxin $12 / 14$ cascade regulates antioxidant capacity in response to chilling in tomato. - Plant Cell Environ. 2017: 1-13, 2017.

Yang, G, Komatsu, S.: Microarray and proteomic analysis of brassinosteroid - and gibberellin-regulated gene and protein expression in rice. - Genomics Proteomics Bioinfor. 2: 7783, 2004.

Yang, C.-J., Zhang, C., Lu, Y.-N., Jin, J.-Q., Wang, X.-L.: The mechanisms of brassinosteroids' action: from signal transduction to plant development. - Mol. Plants 4: 588-600, 2011.

Yang, S., Maeshima, M., Tanaka, Y., Komatsu, S.: Modulation of vacuolar $\mathrm{H}^{+}$-pumps and aquaporin by phytohormones in rice seedling leaf sheaths. - Biol. pharmacol. Bull. 26: 8892, 2003.

Yokota, T., Ogino, Y., Takahashi, N., Saimoto, H., Fujioka, S., Sakurai, A.: Brassinolide is biosynthesized from castasterone in Catharanthus roseus crown gall cells. - Agr. Biol. Chem. 54: 1107-1108, 1990.

Yoshizawa, E., Kaizuka, M., Yamagami, A., Higuchi-Takeuchi, M., Matsui, M., Kakei, Y., Shimada, Y., Sakuta, M., Osada, H., Asami, T., Nakano, T.: BPG3 is a novel chloroplast protein that involves the greening of leaves and related to brassinosteroid signaling. - Biosci. Biotechnol. Biochem. 78: 420-429, 2014.

Yu, J.Q., Huang, L.F., Hu, W.H., Zhou, Y.H., Mao, W.H., Ye, S.F., Nogués, S.: A role for brassinosteroids in the regulation of photosynthesis in Cucumis sativus. - J. exp. Bot. 55: 1135-1143, 2004.

Yuan, L., Shu, S., Sun, J., Guo, S., Tezuka, T.: Effects of 24epibrassinolide on the photosynthetic characteristics, antioxidant system, and chloroplast ultrastructure in Cucumis sativus L. under $\mathrm{Ca}\left(\mathrm{NO}_{3}\right)_{2}$ stress. - Photosynth. Res. 112: 205-214, 2012.

Zhang, S., Wei, Y., Lu, Y., Wang, X.: Mechanisms of brassinosteroids interacting with multiple hormones. - Plant Signal. Behav. 4: 1117-1120, 2009.

Zhang, Y.P., He, J., Yang, S.J., Chen, Y.Y.: Exogenous 24-epibrassinolide ameliorates high temperature-induced inhibition of growth and photosynthesis in Cucumis melo. Biol. Plant. 58: 311-318, 2014.

Zhang, Y.P., Zhu, X.H., Ding, H.D., Yang, S.J., Chen, Y.Y.: Foliar application of 24-epibrassinolide alleviates hightemperature-induced inhibition of photosynthesis in seedlings of two melon cultivars. - Photosynthetica 51: 341349, 2013. 